\section{IMAGEN PAÍS DE COLOMBIA DESDE LA PERSPECTIVA EXTRANJERA}

\author{
Lina María Echeverri Cañas \\ Universidad del Rosario \\ lina.echeverri@urosario.edu.co \\ Enrique ter Horst \\ Colegio de Estudios Superiores de Administración \\ enrique.terhorst@cesa.edu.co \\ José Hernán Parra \\ Universidad Nacional de Colombia \\ jhparrasa@unal.edu.co
}

Cómo citar este artículo/Citation: Echeverri Cañas, L. M.; ter Horst, E.; Hernán Parra, J. (2015). "Imagen país de Colombia desde la perspectiva extranjera". Arbor, 191 (773): a244. doi: http://dx.doi.org/10.3989/arbor.2015.773n3014

Recibido: 15 julio 2014. Aceptado: 12 septiembre 2014.

RESUMEN: Colombia es un país con un posicionamiento histórico negativo en mercados internacionales. Si bien los gobiernos y los prescriptores han dedicado esfuerzos por mejorarla, la percepción del extranjero se mantiene polarizada, es decir, todavía el país es asociado con el café y con el narcotráfico. El presente artículo es el resultado de una investigación cualitativa realizada a extranjeros procedentes de ocho países que registran el mayor número de visitantes en Colombia en el 2013 desde el continente americano: Estados Unidos, Venezuela, Ecuador, Argentina, Perú, Brasil, México y Chile. Como resultado del estudio se encontró que la imagen de Colombia no es unidimensional, es multidimensional. Se logran identificar cinco dimensiones que influyen en la imagen país: el conocimiento del país, la orientación industrial, las actitudes de los visitantes, las percepciones de los prospectos y las preferencias e intereses asociado a su imagen.

PALABRAS CLAVE: Colombia; Imagen país; Percepción; Posicionamiento; Prospectos; Visitantes.

\section{COLOMBIA'S COUNTRY IMAGE FROM THE FOREIGN PERSPECTIVE}

Copyright: (C) 2015 CSIC. Este es un artículo de acceso abierto distribuido bajo los términos de la licencia Creative Commons Attribution-Non Commercial (by-nc) Spain 3.0.

ABSTRACT: Colombia is a country with a negative historical positioning in international markets. Despite efforts by governments and influencers to improve its image, the perception of foreigners remains polarized, being associated with coffee and drug trafficking. This article is the result of a qualitative research conducted on foreign visitors from eight countries in the Americas with the largest number of visitors to Colombia in 2013: The United States, Venezuela, Ecuador, Argentina, Peru, Brazil, Mexico and Chile. The study found that the image of Colombia is not one-dimensional, but multidimensional. It identifies five dimensions that influence country image: knowledge of the country, the industrial orientation, visitor attitudes, perceptions of prospects and preferences and finally interests associated with its image.

KEYWORDS: Colombia; Country Image; Perception; Positioning; Prospects; Visitors. 


\section{INTRODUCCIÓN}

La estrategia de capitalizar la imagen de un país surge de la necesidad de diferenciación de los territorios a través de la identificación de las características de cada lugar, creando incentivos y atractivos para sus visitantes y residentes. Cada país tiene una imagen percibida diferente. Y es la percepción del público extranjero la que contribuye o no a mejorar el posicionamiento de un país en el ámbito internacional. Tradicionalmente en el caso de Colombia la imagen país ha estado vinculada al narcotráfico (Rangel, 1995). Situación que genera un posicionamiento desfavorable para competir en mercados internacionales. Las estrategias promocionales contemporáneas de Colombia buscan reforzar asociaciones favorables con el país y proyectar al público extranjero una imagen distinta. Estas asociaciones se encuentran en la percepción que tiene el público extranjero hacia los productos, marcas, símbolos o personas de un determinado país.

En el 2012, el ingreso de extranjeros a Colombia presentó un incremento de un 7,6\% comparado con el 2011 (Proexport Colombia, 2013). El país emisor más grande de viajeros hacia Colombia fue Estados Unidos. Se registraron 319.302 extranjeros de nacionalidad estadounidense (Proexport Colombia, 2013). Por lo anterior, la intencionalidad de la investigación es identificar las asociaciones que tienen los estadounidenses, sobre la imagen país de Colombia. Los elementos que componen la población fueron personas mayores de 18 años, visitantes y no visitantes extranjeros. Según la Organización Mundial del Turismo (2007), visitante es la persona que viaja a un destino diferente a su lugar de procedencia por una duración inferior a un año, independiente del motivo de viaje (turismo, negocios o personal).

La hipótesis del estudio plantea que Colombia tiene una asociación histórica negativa. Las drogas, la corrupción y la inseguridad son tres aspectos negativos comunes con los que se asocia la imagen país según la perspectiva estadounidense. Los resultados que arrojó la investigación demuestran que la imagen país de Colombia está sujeta a cambios generacionales y que la percepción cambia según la experiencia del visitante.

\section{REVISIÓN DE LA BIBLIOGRAFÍA}

La imagen de un país es la percepción que tienen los consumidores directos, indirectos, reales y potenciales de los países (Valls, 1992). Tiene como finalidad comunicar de manera favorable la imagen de un lugar y que esta sea consecuente con la realidad (Dinnie et al., 2010). Desde la perspectiva histórica, el concepto de imagen país ha estado asociado al conjunto de percepciones que tienen las personas sobre los productos originarios de un país determinado (Papadopoulos \& Heslop, 1993). La imagen un país está representada por un conjunto de creencias, mitos, historia y cultura (Gertner \& Kotler, 2002). La imagen de país es la representación o asociación mental de un determinado país, más allá si son atributos reales o ficticios de la nación en cuestión (Capriotti, 2008). La formación de la imagen país es por naturaleza un proceso subjetivo y está expuesta a cambios a lo largo del tiempo (Dikčius \& Stankevičienè, 2010).

La imagen es una idea y un juicio de valor de un público hacia un determinado país, tema o un producto. Es la forma en que el público crea en su imaginario la manera como se anuncia un país (Plânlama Teşkilât, 2000). La imagen país es el conjunto de significados que cobran forma en la mente de las personas a partir de lo que escuchan, dicen y recuerdan de un destino específico. Esta explicación demuestra que la imagen está formada por un gran número de factores que inciden en las conductas de las personas hacia los objetos (Tunca, 2008). Después de un proceso de percepción, la imagen de un país cobra forma en la memoria del individuo. Los juicios personales sobre sujetos, objetos, ambientes culturales, la estructura política, la historia, entre otros, se convierte en el principal proceso de percepción (Dikčius \& Stankevičienè, 2010).

Si el público aprueba una percepción de un país, se dice que tiene buena imagen. Su si la desaprueba se dice que tiene una mala imagen. Los términos "buena imagen" y "mala imagen" tal como se utilizan hoy en día rara vez revelan las respuestas relativas de hecho o de ficción sobre la percepción de una imagen. No siquiera representan un juicio de valor ético y moral. Simplemente reflejan la respuesta positiva o negativa que hacen las personas cuando están expuestas a una imagen país (Turney, 2000). Las imágenes, son "imágenes en nuestras cabezas", en la medida que una imagen retrate la realidad externa, será más significativa para quienes la perciben (Tunca, 2008). La imagen no es ajena al concepto de la marca país. La primera, depende de las percepciones populares y la segunda es una estrategia que permite consolidar una imagen deseada de un país en mercados internos y externos (Bhakar, Bhakar, \& Bhakar, 2013). El concepto de marca país, busca materializar el proceso subjetivo hacia un aprendizaje experiencial de un visitante o un inversionista (de Moura Engracia Giraldi, Ikeda, \& Campomar, 2011). 
Las características de la imagen país son atributos percibidos por los visitantes al país, que son aquellos individuos que a partir de la percepción y su posterior experimentación en el lugar, pueden definir su impresión y comprensión por medio de palabras y símbolos que trasmitan su sentimiento (Balabanis \& Diamantopoulos, 2011). Son ellos quienes al regresar a sus lugares de origen, trasmitirán su sentimiento y experiencia vivida del país visitado. Estas experiencias pueden ser los paisajes, la infraestructura, la modernidad, lo clásico, la historia y cultura, el trato recibido de los ciudadanos del país, o empresas y/o productos que hayan marcado un diferencial en sus mentes (Martínez \& Alvarez, 2010).

Existen mediciones de marca país que se realizan con el análisis de siete variables: turismo, inversión e inmigración, producto y exportaciones, gobierno, cultura y patrimonio, y población de un país (HarrisonWalker, 2011). Por otro lado, hay países que planifican una estrategia para realizar un seguimiento y medir lo que está ocurriendo en el país versus a lo que se quiere llegar para determinar en qué medida se están alcanzando los objetivos planteados (Zenker \& Martin, 2011). Las imágenes que se tiene sobre un país generalmente están relacionadas con la manera en que se perciben como destinos turísticos, lugares para invertir o lugares para comprar las marcas preferidas por los clientes (Wang et al., 2012). El turismo es el vínculo más directo entre la imagen positiva y el crecimiento económico de un país (Stock, 2009).

La imagen de un país puede ser expresada a través de percepciones generalizadas y también puede reducirse a una serie de actitudes positivas y negativas dependiendo de las impresiones que tenga un visitante, inversionista o habitante sobre un país (Martínez \& Alvarez, 2010). De una manera más precisa se refuerzan los estereotipos se articulan con los juicios de valor y con las asociaciones mentales que tengan las personas frente a un destino determinado (Diamantopoulos, Schlegelmilch, \& Palihawadana, 2011). La imagen se construye según la reputación que tenga un país. En este sentido, la imagen y la reputación son dos componentes interrelacionados, es decir, la imagen es lo que se proyecta al mundo, mientras que la reputación es la información recibida dada por la experiencia del visitante o inversionista (Whetten \& Mackey, 2001).

Los países buscan ser diferenciados, así sus atributos naturales sean similares. La diferenciación, es un requisito permanente en la construcción de una identidad de marca, y su forma es la imagen misma de una empresa, producto o país que se expone ante un mercado determinado (Anholt, s.f.). Para un país, su imagen implica considerar el conjunto de características, valores y creencias con las que la sociedad se auto identifica y se auto diferencia de las demás (Jetter \& Chen, 2011). Los gobiernos de diferentes países del mundo están tomando un enfoque proactivo en el fortalecimiento de su imagen país, a través del crecimiento del turismo, el fomento a la inversión extranjera y las exportaciones, y la fuerte influencia política que ejercen sobre otros países (de Moura Engracia Giraldi, Ikeda, \& Campomar, 2011).

\section{METOdOLOGÍA}

La investigación aplicada es de carácter cualitativo. La primera aproximación importante a la investigación cualitativa es la fenomenología, es decir, el estudio descriptivo de cómo los individuos experimentan un fenómeno (Merriam, 2009). En la investigación el fenómeno objeto de estudio hace referencia a las percepciones, impresiones y asociaciones que tienen los extranjeros sobre la imagen de Colombia.

La técnica cualitativa permite alimentar el trabajo investigativo a partir del análisis de variables previamente establecidas que fueron de utilidad para identificar y las percepciones sobre la imagen país de Colombia. Para efectos de la investigación, se denominó al sujeto de estudio como visitante y prospecto ${ }^{1}$, partiendo de la base que este calificativo permitirá, con mayor amplitud, delinear perfiles y rasgos sino también la percepción de la imagen país de Colombia. A continuación se explican los componentes de la investigación cualitativa:

a. Población. Para la investigación se determinó que el alcance del estudio serían los ocho países del continente americano que registran el mayor número de visitantes extranjeros que ingresaron a Colombia durante el 2013 según Migración Colombia (2014). Los países objeto de estudio fueron:

1. Estados Unidos

2. Venezuela

3. Ecuador

4. Argentina

5. Perú

6. Brasil

7. México

8. Chile 
Los elementos que componen la población son todos los visitantes extranjeros. Según la Organización Mundial de Turismo (2007), visitante es la persona que viaja a un destino diferente a su lugar de procedencia por una duración inferior a un año, independiente del motivo de viaje (turismo, negocios o personal). Las unidades de muestreo, son todos los visitantes extranjeros mayores de 18 años procedentes de Estados Unidos, Venezuela, Ecuador, Argentina, Perú, Brasil, México y Chile.

b. Muestra. Para la determinación del tamaño de la muestra se aplicó una prueba piloto a personas que han visitado y no han visitado a Colombia. La muestra piloto se realizó con dos propósitos: a) probar el instrumento de recolección de información (Encuesta) y b) calcular los estimadores (p) de las variables más importantes del estudio, que permitirán calcular el error estándar de estimación, estimador básico para la determinación del tamaño de la muestra. En este caso, la variable más importante del estudio fue: posicionamiento de imagen país por asociación productiva.

El muestreo aplicado fue aleatorio simple. El muestreo aleatorio simple exige que cada unidad tenga la probabilidad equitativa de ser incluida en la muestra. (Malhotra, 2010). Para determinar la muestra se consideró el número de visitantes extranjeros procedentes del continente americano que ingresaron a Colombia durante el 2013. De acuerdo con Migración Colombia (2014), al país ingresaron 1'832.098 extranjeros procedentes de ocho países. Estos ocho países del continente americano son los que representan el mayor flujo de llegadas a Colombia (ver Figura 1).

Por ser una población conocida, se aplicó la siguiente fórmula aplicada a cada país objeto de estudio.

$$
n=\frac{N^{*} Z^{2 *} P^{*}(1-P)}{N^{*} e^{2}+Z^{2 *} P^{*}(1-P)}
$$

Donde,

$N$ Universo.

$n$ es el tamaño necesario de la muestra.

Z margen de confiabilidad o número de unidades de desviación estándar en la distribución normal que producirá el nivel deseado de confianza (para un nivel de confianza de $95 \%$ o un $\alpha=0,05, Z=1,96)$.

$P$ proporción estimada para las variables categóricas de la población objeto de estudio $(P=0,5)$.

E error estándar relativo de estimación por debajo del [7\%].

Figura 1. Top 8 de número de visitantes extranjeros procedentes del continente americano que ingresaron a Colombia durante 2012

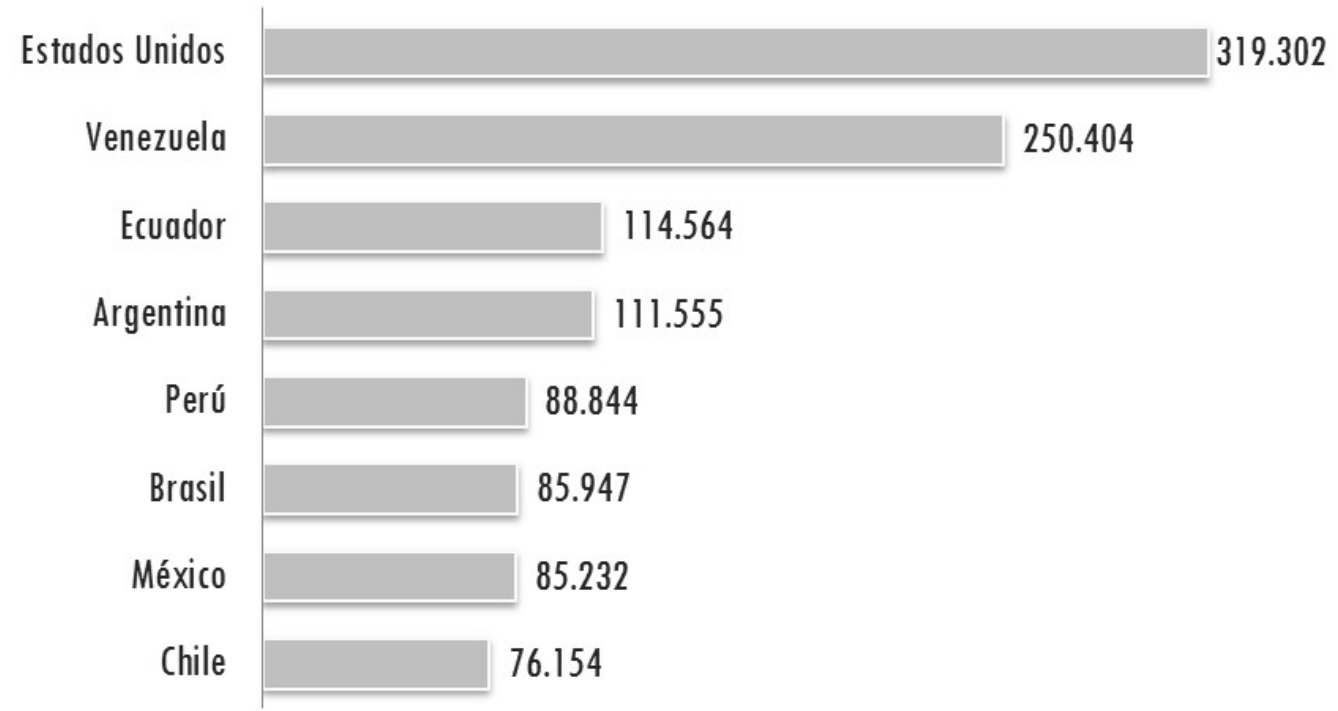

Fuente: Adaptado de Migración Colombia (2013). 
El valor muestral fue de 188 encuestas por país. Pero se prefirió considerar 190 por destino. Con la finalidad de lograr el mayor grado de representatividad, los sujetos fueron elegidos aleatoriamente, solo con el condicionante que fueran personas mayores de 18 años. Para balancear la muestra, se dividió en dos grupos: visitantes y prospectos.

En el Cuadro I se puede observar el cálculo del tamaño muestral por país y según la categoría de visitantes.

Las variables sociodemográficas consideradas para el estudio fueron: tipología (visitante o prospecto), edad, género, nivel de escolaridad y estado civil. En el Cuadro II se puede observar el perfil sociodemográfico de las personas encuestas.

c. Delimitación Espacial. La investigación empírica se realizó en Estados Unidos, Venezuela, Ecuador, Ar- gentina, Perú, Brasil, México y Chile. Se aplicaron encuestas directas a personas mayores de 18 años nativos de los países objeto de estudio, entre ellos visitantes y prospectos de Colombia. A través de muestreo aleatorio se aplicaron 1.544 encuestas.

d. Técnica de recolección de información. La técnica empleada fue la encuesta estructurada. Esta técnica está orientada a establecer contacto directo con personas que se consideran fuente de información. La encuesta se soporta en un cuestionario flexible que tiene como propósito obtener información más espontánea y abierta. Durante las encuestas realizadas se profundizó en información de interés para el estudio. Se diseñaron dos instrumentos, para visitantes y prospectos. Ambos instrumentos se sometieron al método Delphi, con la finalidad que fueran evaluados por expertos. El instrumento se diseñó en el idioma español,

Cuadro I. Tamaño muestral por país

\begin{tabular}{|c|c|c|c|}
\hline País & $\begin{array}{l}\text { Tamaño Muestral } \\
\text { (Visitantes) }\end{array}$ & $\begin{array}{l}\text { Tamaño Muestral } \\
\text { (Prospectos) }\end{array}$ & $\begin{array}{l}\text { Total por } \\
\text { país }\end{array}$ \\
\hline Estados Unidos & $\begin{array}{l}\mathrm{n}_{1}=95 \text { personas mayores de } 18 \text { años proce- } \\
\text { dentes de Estados Unidos que han visitado } \\
\text { a Colombia }\end{array}$ & $\begin{array}{l}\mathrm{n}_{1}=95 \text { personas mayores de } 18 \text { años } \\
\text { procedentes de Estados Unidos que no } \\
\text { han visitado a Colombia }\end{array}$ & 190 \\
\hline Venezuela & $\begin{array}{l}\mathrm{n}_{1}=95 \text { personas mayores de } 18 \text { años pro- } \\
\text { cedentes de Venezuela que han visitado a } \\
\text { Colombia }\end{array}$ & $\begin{array}{l}n_{1}=95 \text { personas mayores de } 18 \text { años } \\
\text { procedentes de Venezuela que no han } \\
\text { visitado a Colombia }\end{array}$ & 190 \\
\hline Ecuador & $\begin{array}{l}n_{1}=95 \text { personas mayores de } 18 \text { años pro- } \\
\text { cedentes de Ecuador que han visitado a } \\
\text { Colombia }\end{array}$ & $\begin{array}{l}\mathrm{n}_{\mathbf{1}}=\mathbf{9 7} \text { personas mayores de } 18 \text { años } \\
\text { procedentes de Ecuador que no han vi- } \\
\text { sitado a Colombia }\end{array}$ & 192 \\
\hline Argentina & $\begin{array}{l}n_{1}=95 \text { personas mayores de } 18 \text { años pro- } \\
\text { cedentes de Argentina que han visitado a } \\
\text { Colombia }\end{array}$ & $\begin{array}{l}\mathrm{n}_{1}=96 \text { personas mayores de } 18 \text { años } \\
\text { procedentes de Argentina que no han } \\
\text { visitado a Colombia }\end{array}$ & 191 \\
\hline Perú & $\begin{array}{l}\mathbf{n}_{1}=95 \text { personas mayores de } 18 \text { años proce- } \\
\text { dentes de Perú que han visitado a Colombia }\end{array}$ & $\begin{array}{l}\mathrm{n}_{1}=95 \text { personas mayores de } 18 \text { años } \\
\text { procedentes de Perú que no han visita- } \\
\text { do a Colombia }\end{array}$ & 190 \\
\hline Brasil & $\begin{array}{l}\mathrm{n}_{1}=95 \text { personas mayores de } 18 \text { años proce- } \\
\text { dentes de Brasil que han visitado a Colombia }\end{array}$ & $\begin{array}{l}\mathrm{n}_{1}=\mathbf{9 8} \text { personas mayores de } 18 \text { años } \\
\text { procedentes de Brasil que no han visi- } \\
\text { tado a Colombia }\end{array}$ & 193 \\
\hline México & $\begin{array}{l}\mathrm{n}_{1}=95 \text { personas mayores de } 18 \text { años pro- } \\
\text { cedentes de México que han visitado a } \\
\text { Colombia }\end{array}$ & $\begin{array}{l}\mathrm{n}_{1}=\mathbf{9 8} \text { personas mayores de } 18 \text { años } \\
\text { procedentes de México que no han vi- } \\
\text { sitado a Colombia }\end{array}$ & 193 \\
\hline Chile & $\begin{array}{l}n_{1}=95 \text { personas mayores de } 18 \text { años proce- } \\
\text { dentes de Chile que han visitado a Colombia }\end{array}$ & $\begin{array}{l}\mathrm{n}_{1}=\mathbf{1 1 0} \text { personas mayores de } 18 \text { años } \\
\text { procedentes de Chile que no han visita- } \\
\text { do a Colombia }\end{array}$ & 205 \\
\hline \multicolumn{3}{|c|}{ Tamaño Total de la Muestra } & 1.544 \\
\hline
\end{tabular}

Fuente: Elaboración propia 
Cuadro II. Perfil sociodemográfico de las personas encuestadas

\begin{tabular}{|c|c|c|c|c|c|}
\hline & & \multicolumn{2}{|c|}{ Visitantes $(n=760)$} & \multicolumn{2}{|c|}{ Prospectos $(n=784)$} \\
\hline & & Frecuencia & Porcentaje & Frecuencia & Porcentaje \\
\hline \multirow{2}{*}{ Género } & Femenino & 342 & $45 \%$ & 430 & $57 \%$ \\
\hline & Masculino & 418 & $55 \%$ & 330 & $43 \%$ \\
\hline \multirow{4}{*}{ Edad } & Entre 18 y 28 años & 165 & $22 \%$ & 309 & $41 \%$ \\
\hline & Entre 29 y 39 años & 324 & $43 \%$ & 235 & $31 \%$ \\
\hline & Entre 40 y 50 años & 191 & $25 \%$ & 140 & $18 \%$ \\
\hline & Más de 50 años & 80 & $11 \%$ & 76 & $10 \%$ \\
\hline \multirow{5}{*}{ Educación } & Básica & 9 & $1 \%$ & 50 & $7 \%$ \\
\hline & Media & 42 & $6 \%$ & 128 & $17 \%$ \\
\hline & Técnica & 137 & $18 \%$ & 206 & $27 \%$ \\
\hline & Pregrado & 291 & $38 \%$ & 260 & $34 \%$ \\
\hline & Posgrado & 281 & $37 \%$ & 116 & $15 \%$ \\
\hline \multirow{5}{*}{ Estado Civil } & Soltero & 289 & $38 \%$ & 373 & $49 \%$ \\
\hline & Casado & 357 & $47 \%$ & 269 & $35 \%$ \\
\hline & Unión Libre & 35 & $5 \%$ & 62 & $8 \%$ \\
\hline & Separado & 68 & $9 \%$ & 43 & $6 \%$ \\
\hline & Viudo & 11 & $1 \%$ & 13 & $2 \%$ \\
\hline
\end{tabular}

Fuente: elaboración propia.

Base: 1.544

inglés y portugués. El instrumento diseñado tiene cerca de 20 preguntas de tipo cualitativo que permitieran recoger información en tres campos del estudio:

- Impresiones sobre la imagen de Colombia

- Asociación simbólica sobre la imagen país de Colombia

\section{- Preferencias e intereses en Colombia}

Se aplicaron los cuestionarios a través del contacto personal. La información recopilada se tabuló los datos inicialmente en hojas de cálculo de EXCEL y una vez codificadas las bases de datos, se realizó el procesamiento estadístico de la información recogida mediante los sistemas estadísticos SPSS, SPAD.N y R.

e. Análisis. En el estudio se realizaron cuatro tipos de análisis, Bi-variado, Análisis de Correspondencia simple (ACS), análisis de correspondencia múltiple (ACM), análisis de conglomerados o Clúster y redes bayesianas.

\section{RESULTADOS}

La reputación de un país se construye sobre las ideas, la percepción y las experiencias que tienen los visitantes o inversionistas. Especialmente es la percepción la que recrea el concepto de imagen país, como un conjunto de creencias, ideas e impresiones que una persona tiene sobre un objeto (Kotler et al., 2013). La imagen país condiciona las actitudes y acciones de las personas (Papadopoulos \& Heslop, 1993). Los países tienen una preocupación constante sobre la imagen que proyectan en mercados internacionales. Especialmente porque han adoptado e implementado estrategias de diferenciación para estimular el turismo y la inversión económica. En este sentido, Colombia es un país que no es ajeno a la percepción que tiene el mercado internacional.

En el posicionamiento de Colombia existen dos tipos de asociaciones: una productiva y positiva dada por los resultados del sector cafetero, y otra, negativa que recoge dos temas críticos: el narcotráfico y el terrorismo. El proceso de mejorar la imagen país de Colombia, emerge como una búsqueda por lograr una proyección positiva al exterior, así como el gestar la 
reunión de los intereses e íconos que logren la construcción de la identidad nacional.

El relacionamiento con otros países ha motivado al gobierno colombiano a ser partícipe activo en los procesos de integración comercial en América y Europa. El propósito misional de las relaciones comerciales es incentivar el crecimiento económico a partir de exportaciones, inversión extranjera directa y turismo. Para cumplir este propósito, Colombia debe fortalecer su imagen país, especialmente con países del continente americano, puesto que son mercados relevantes en términos de acuerdos comerciales, y especialmente en el impacto que tienen en turismo.

Los resultados del estudio que ponen en relieve la importancia de la formulación de un modelo de proyección país orientado a mejorar la imagen de Colombia en mercados internacionales. La percepción que tienen los extranjeros sobre la imagen país de Colombia está condicionada por diferentes factores sicológicos, como: a) las impresiones de la imagen de un país generado por la experiencia (para quienes la han visitado), b) las creencias entorno a un país (para quienes lo han visitado y no lo han visitado) y los elementos con los que se asocia a un país a través de su población, símbolos, preferencias, entre otros. A continuación se exponen los resultados más relevantes del estudio realizado a 1.544 extranjeros.
La imagen país de Colombia es sensible a las percepciones de los extranjeros, especialmente de los países principales emisores de visitantes en el continente americano. La percepción es un elemento de comportamiento humano, y como tal, está sujeta a las influencias que dan forma a otros aspectos de la conducta. La experiencia de cada individuo se combina de manera compleja para determinar su reacción a un estímulo dado. La imagen de un país, motiva en las personas el deseo de visitar, vivir, trabajar o invertir en el país. Estos motivos son causados por la información y creencias que se tiene del lugar.

La imagen país de Colombia tiene un posicionamiento polarizado, pero que aún conserva una alta asociación histórica negativa y una asociación productiva tradicional en el continente americano. De acuerdo con los resultados del estudio, el $27 \%$ de los visitantes y prospectos extranjeros coinciden en asociar la palabra "Colombia" con las drogas, el terrorismo, la inseguridad y la corrupción. Seguido de un $20 \%$ del total de los entrevistados que lo asocian con el café. Como se puede observar en la Figura 2, la palabra "Colombia" tiene diversas asociaciones dependiendo si es visitante o prospecto. El visitante asocia la palabra "Colombia" con gente amable y acogedora, mientras el prospecto la asocia con atributos negativos ya mencionados.

Figura 2. ¿Qué es lo primero que piensa cuando oye la palabra "Colombia"?

Novelas
Negocios
$\square$ Turismo
$\square$ Arte, Cultura, Gastronomía y Deportes
$\square$ Café

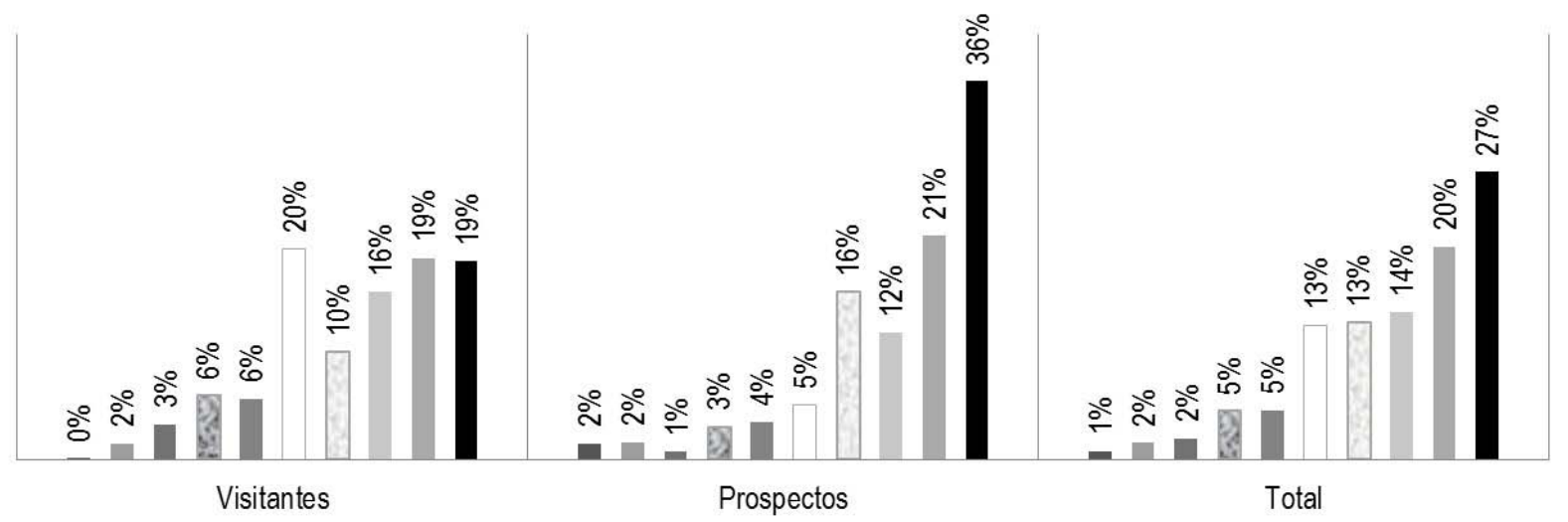

Fuente: elaboración propia. Base: 1.554

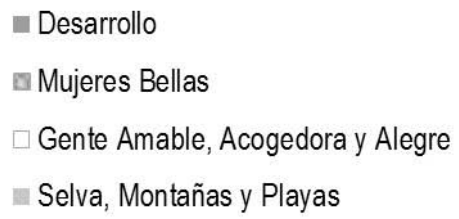

- Drogas, Terrorismo, Inseguridad y Corrupción 
La experiencia del visitante modifica su percepción sobre la imagen de Colombia. Lo anterior expone la necesidad de proponer un modelo de proyección país que sea incluyente, dirigido especialmente a los extranjeros del continente que no ha visitado a Colombia, y que han mantenido en su imaginario colectivo una percepción negativa sobre el país.

Atributos como la selva, montañas, playas, arte, cultura, gastronomía y deportes, fueron expuestos por los entrevistados. Esto indica cómo la imagen de Colombia ha logrado explorar nuevas áreas de interés para el visitante muy diferentes a las percepciones tradicionales. Es en estos atributos que la estrategia de marca país debe enfocarse, ya que Colombia no puede concentrarse en posicionamientos de carácter productivo, sino enfocarse en otros elementos que reconoce el visitante y aún el prospecto.

El total de extranjeros entrevistados (visitantes y prospectos) asocian a Colombia con aspectos positivos como: la gente amable (29\%), la naturaleza y los paisajes (20\%) y la alegría (14\%) (ver Figura 3).
En lo referente a aspectos negativos, los extranjeros asocian la imagen del país con las drogas (22\%), la guerrilla $(21 \%)$, el narcotráfico $(21 \%)$ y la violencia (16\%) (ver Figura 4). Es de notar, que Colombia mantiene una asociación histórica negativa en lo referente al narcotráfico. Quienes han visitado a Colombia asocian su imagen con la guerrilla (23\%) y aquellos que aún no lo han visitado lo asocian con las drogas (27\%).

El $45 \%$ de visitantes y prospectos coinciden en que el café es el símbolo que representa a Colombia. Para el $18 \%$ de los extranjeros, hay otros símbolos asociados como la música, la chiva ${ }^{2}$ y el sombrero vueltiao (ver Figura 5).

El $22 \%$ de los extranjeros asocian a Colombia con la cantante Shakira (ver Figura 6). El 18\% relacional la imagen del país con amigos y familiares. Figuras presidenciales y deportistas ocupan el tercer y cuarto lugar en el total de las respuestas. Como es el caso del expresidente Álvaro Uribe, que después de cuatro años desde su presidencia, sigue manteniéndose como un líder opinión, opositor del Gobierno del presidente Juan Manuel Santos.

Figura 3. ¿En una sola palabra describa algo positivo de Colombia?

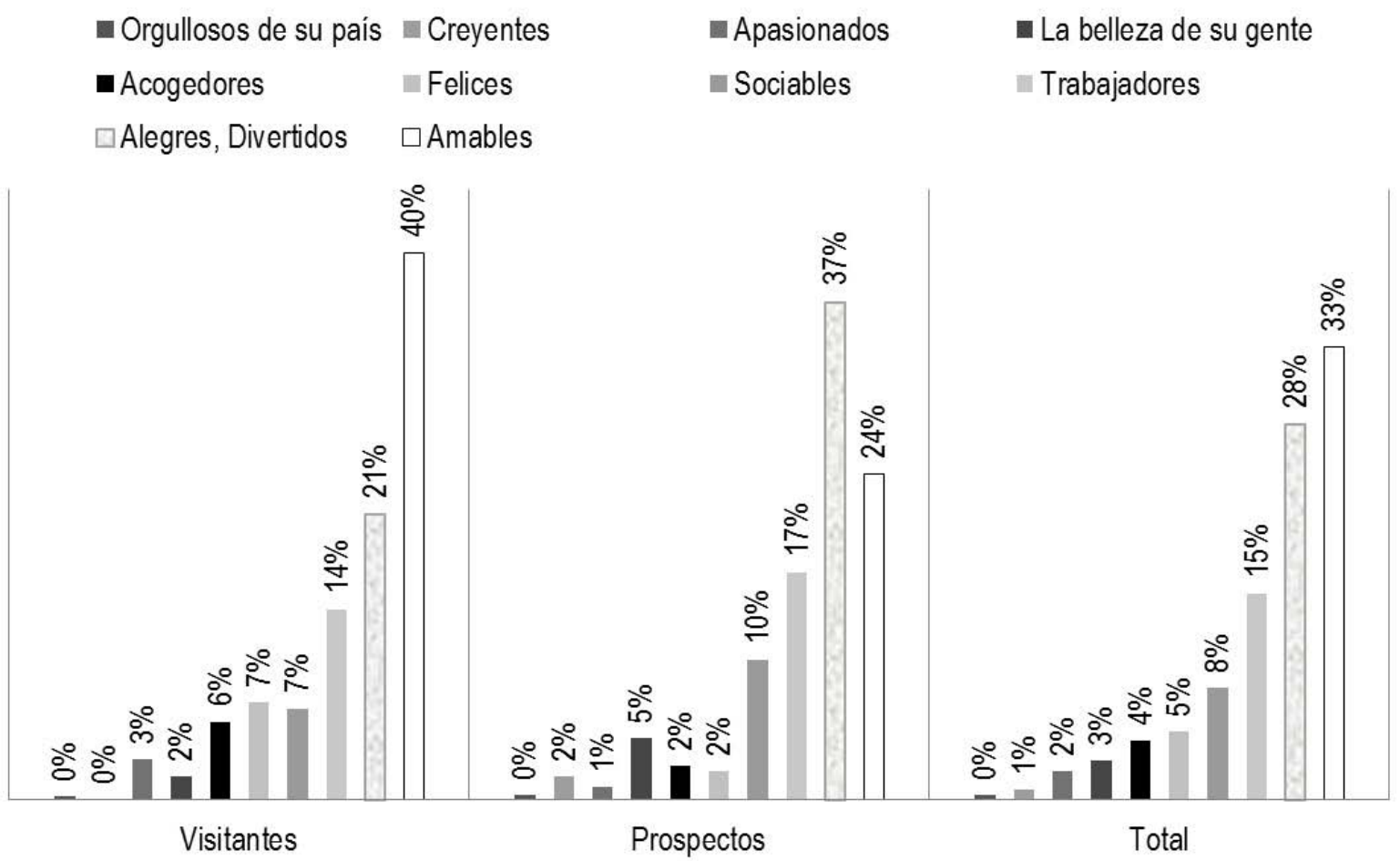

Fuente: elaboración propia.

Base: 1.554 
Figura 4. ¿En una sola palabra describa algo negativo de Colombia?

- Congestión Vehicular ${ }^{-}$Crimen

- Terrorismo

- Inseguridad

$\square$ Guerrilla

\section{口 Drogas}

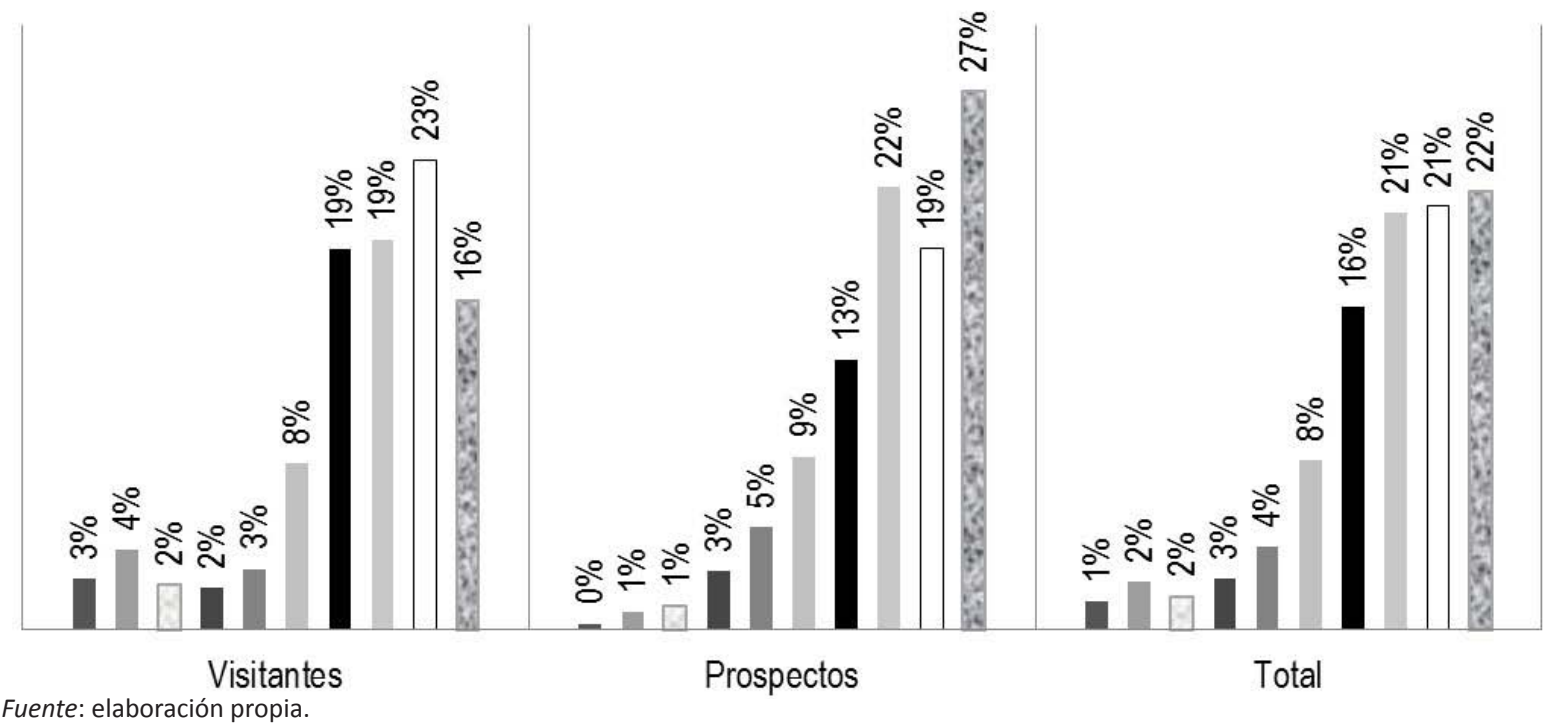

$\square$ Corrupción

- Violencia
- Pobreza

- Narcotráfico

Base: 1.554

Figura 5. ¿Qué símbolo representa a Colombia?

$\square$ Piedras preciosas
$\square$ Gente
$\square$ Artistas y Deportistas
$\square$ Bandera de Colombia
-Música, Chiva y Sombrero Vueltiao

- Piedras preciosas

$$
\begin{aligned}
& \text { Juan Valdéz } \\
& \text { Drogas } \\
& \text { Flores } \\
& \text { a Montañas, aves y ríos } \\
& \text { Café }
\end{aligned}
$$

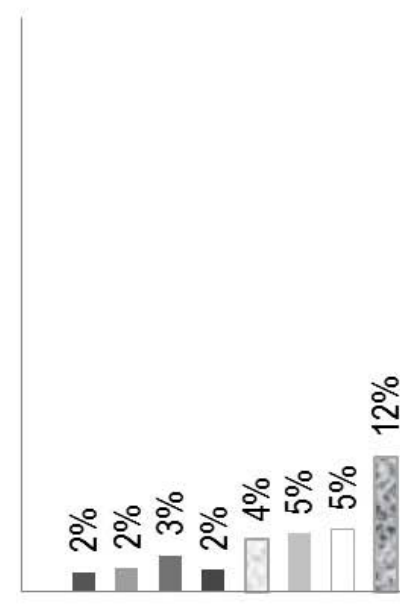

Visitantes

Fuente: elaboración propia.

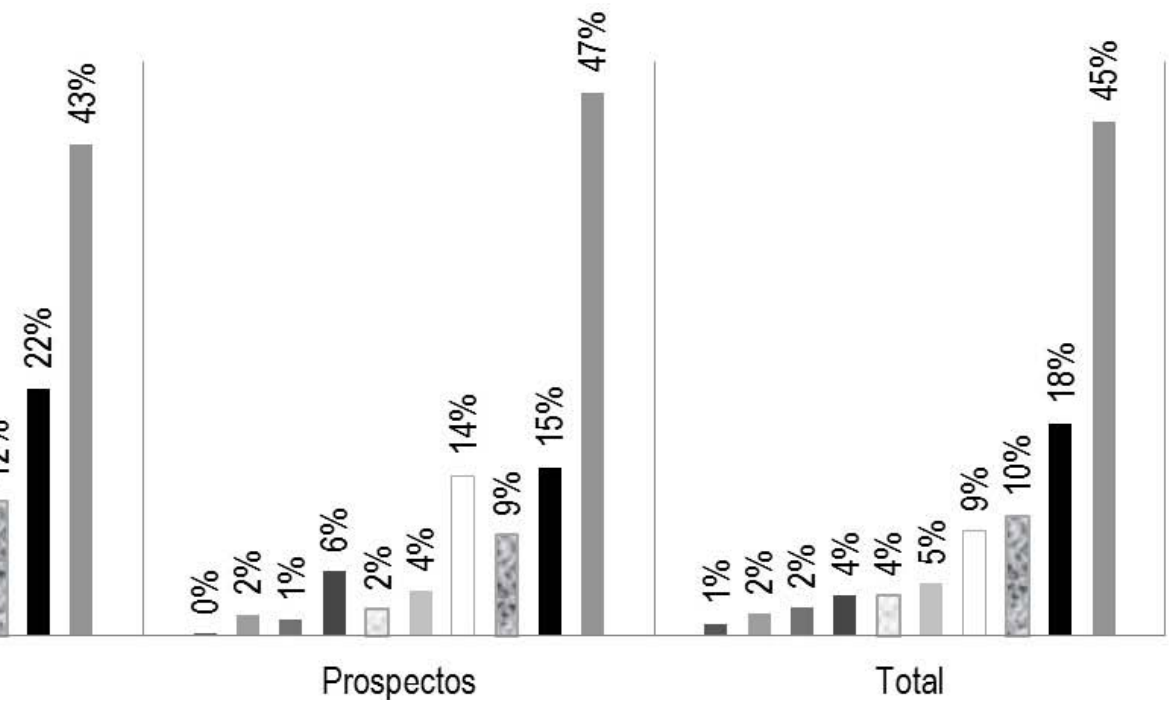
Base: 1.554 
Figura 6. Cuando se menciona a Colombia, ¿̇con qué persona la asocia?

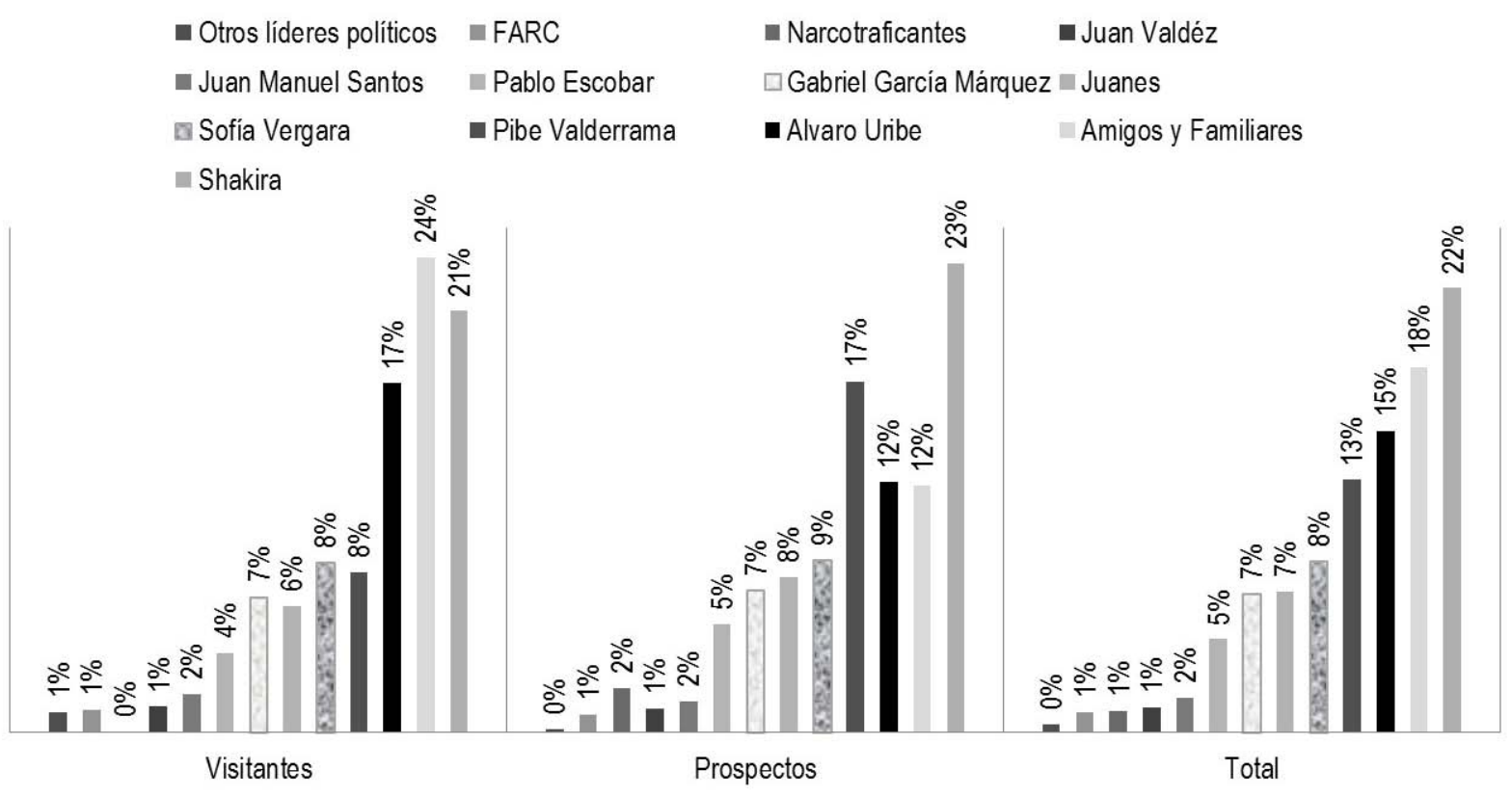

Fuente: elaboración propia.

Base: 1.554

En el análisis de correspondencia aplicado al grupo de visitantes se consideró la relación existente entre variables demográficas (edad y país de origen) con las variables asociadas a la imagen país de Colombia. Según el Test Chi Cuadrado hay una asociación significativa (ver Cuadro III):

Cuadro III. Test Chi Cuadrado de Imagen país de Colombia y variables demográficas de los visitantes

\begin{tabular}{|l|c|c|c|c|}
\hline \multirow{2}{*}{ Variables } & \multicolumn{2}{|c|}{ Edad } & \multicolumn{2}{c|}{ País de Origen } \\
\cline { 2 - 5 } & $\mathbf{X}^{2}$ & Sig. & $\mathbf{X}^{\mathbf{2}}$ & Sig. \\
\hline $\begin{array}{l}\text { ¿Qué es lo primero que piensa cuándo oye la palabra } \\
\text { “Colombia”? }\end{array}$ & 28,1 &, 404 & 326,9 &, 000 \\
\hline ¿En una sola palabra describa algo positivo de Colombia? & 62,2 &, 000 & 590,4 &, 000 \\
\hline ¿En una sola palabra describa algo negativo de Colombia? & 54,9 &, 001 & 666,9 &, 000 \\
\hline ¿Qué características tienen los colombianos? & 28,8 &, 227 & 432,8 &, 000 \\
\hline
\end{tabular}

Fuente: elaboración propia.

Base: 760

En la Figura 7 se observa que los visitantes más jóvenes procedentes de México y Brasil asocian a Colombia con drogas y terrorismo. Los estadounidenses de 29 y 39 años asocian al país con la selva, montañas y playa, los argentinos con negocios, los peruanos con turismo, los chilenos entre 40 y 50 años con gente amable y acogedora; y los ecuatorianos mayores de 50 años con arte, cultura, gastronomía y mujeres bellas.

Una vez aplicado el Análisis de Correspondencia, se encontró que existe relación entre los aspectos positivos asociados a Colombia con el perfil demográfico (edad y país de origen) de los visitantes extranjeros.
Como se aprecia en la Figura 8, los venezolanos entre 40 y 50 años asocian a Colombia con aspectos positivos como la naturaleza, las mujeres bellas y la gente amable. Los mexicanos mayores de 50 años indican que los aspectos positivos de Colombia son: el turismo, el arte, la cultura y el deporte. Para los peruanos y ecuatorianos, entre 29 y 39 años, la imagen país de Colombia se asocia con aspectos positivos como los negocios y el café. Los chilenos y argentinos por su parte, los más jóvenes de la muestra, indicaron que el buen clima y la alegría son los aspectos positivos que proyecta Colombia. 
Figura 7. Análisis de correspondencia entre lo que piensan los visitantes extranjeros cuando oyen la palabra Colombia y variables demográficas: país de origen y edad

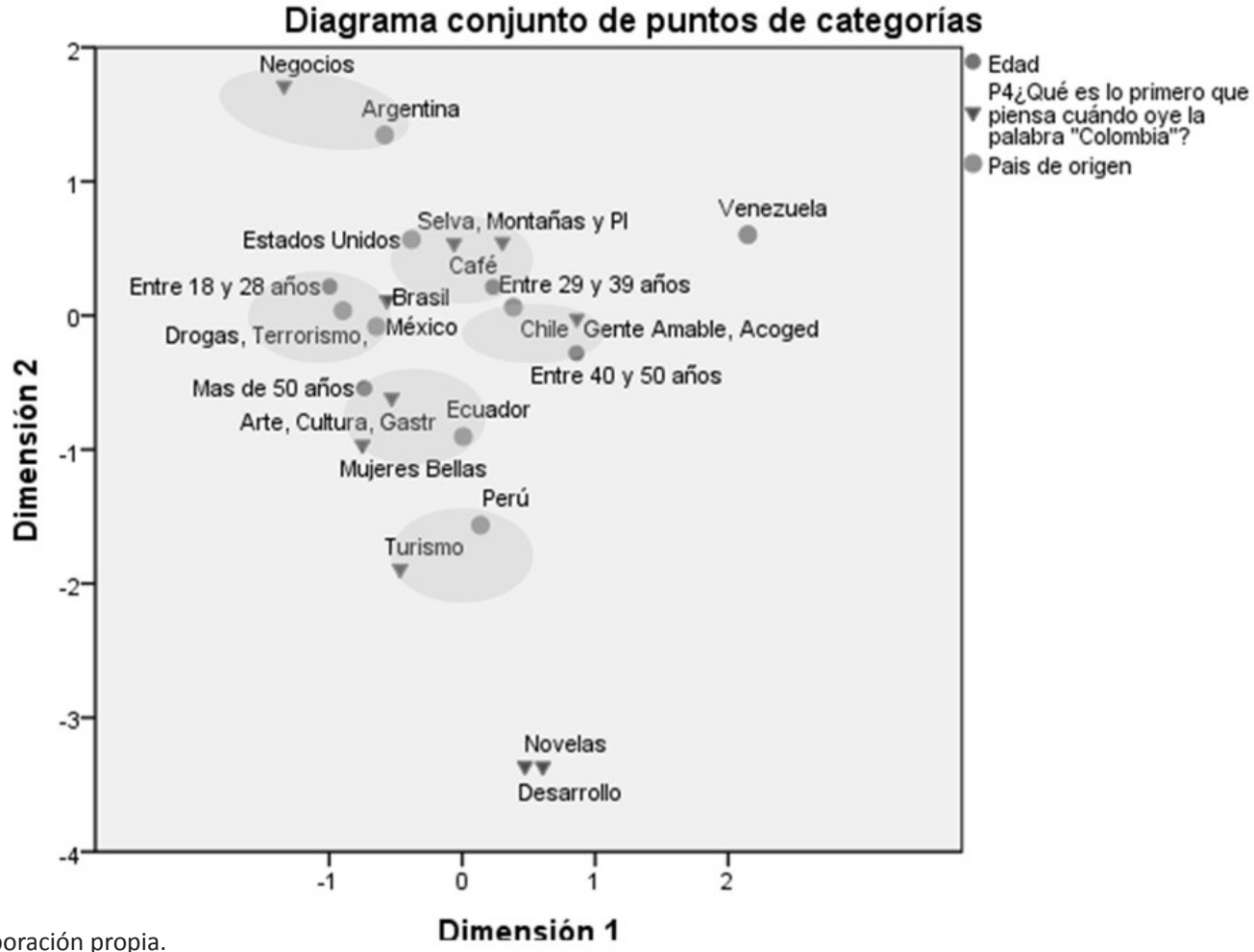

Figura 8. Análisis de correspondencia entre los aspectos positivos de Colombia y variables demográficas: país de origen y edad de los visitantes extranjeros

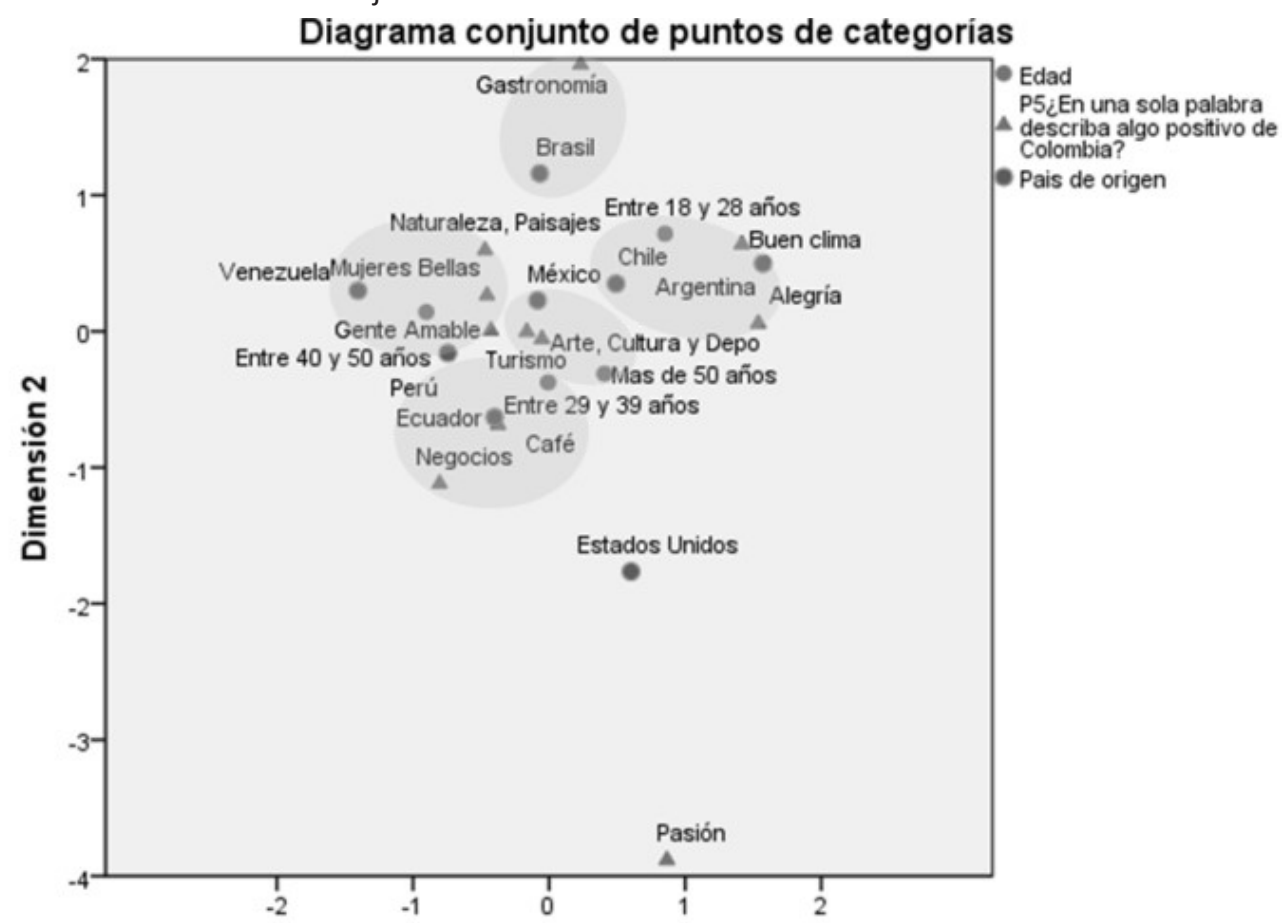

Fuente: elaboración propia.

Dimensión 1 
Lo anterior explica la diversidad de posicionamientos que tiene la imagen país que proyecta Colombia al mercado americano. Situación que debe evaluar la organización a cargo de la estrategia de Marca País Colombia.

Los visitantes más jóvenes de origen estadounidense y brasilero señalan que Colombia está asociada negativamente con las drogas, la inseguridad, el terrorismo y la congestión vehicular. Los mexicanos entre 29 y 39 años consideran que la imagen de Colombia está vinculada a la corrupción. Los chilenos, argentinos y peruanos relacionan a Colombia con el crimen y la guerrilla. Los venezolanos adultos mencionan que el narcotráfico es un aspecto negativo de Colombia. Y los ecuatorianos asocian a Colombia con la violencia. Los visitantes jóvenes y adultos coinciden en que la imagen de Colombia está relacionada con el narcotráfico (ver Figura 9).

En la Figura 10 se puede observar que los peruanos y venezolanos consideran que los colombianos son acogedores, sociables y orgullosos de su país. Para los argentinos, el perfil del colombiano está estrechamente relacionado con la amabilidad. Para los estadounidenses, brasilero, ecuatoriano y chileno, el colombiano se caracteriza por ser alegre y divertido. $Y$ para los visitantes procedentes de México, la felicidad es una característica propia del colombiano.

Los resultados de la investigación presentan a continuación las apreciaciones y representaciones simbólicas que tienen los extranjeros sobre la imagen país de Colombia. En el Análisis de Correspondencia aplicado al grupo de visitantes se consideró la relación existente entre variables demográficas (edad y país de origen) con las variables vinculadas a la asociación simbólica de la imagen país de Colombia. Según el Test Chi Cuadrado hay una asociación significativa (ver Cuadro IV).

El color está estrechamente vinculado a los estados de ánimo, sentimientos y emociones. Al grupo de visitantes se les preguntó sobre el color y olor (aroma) que más se relaciona con el país. Los extranjeros mostraron respuestas diferentes en términos de asociación del país con el color. Los peruanos asocian a Colombia con el blanco, los brasileros con el café y el verde, los estadounidenses con el azul, los venezolanos con el rojo; y los argentinos y ecuatorianos con el amarillo (ver Figura 11). Mientras que la percepción de color y el olor es subjetiva, hay algunos efectos de color que tienen un significado universal. Colores en la zona roja del espectro de color se conocen como colores cálidos como el rojo, naranja y amarilla. Estos colores cálidos evocan emociones que van desde sentimientos de calidez y confort a los sentimientos de ira y hostilidad (Elliot \& Maier, 2012). Argentina Ecuador y Venezuela asocian a Colombia con estos colores. Cabe anotar que estos tres países suramericanos representan el turismo emisor más alto hacia Colombia.

Estados Unidos asocia a Colombia con el azul. Este color se relaciona con la calma, pero también se asocia a sentimientos de tristeza o indiferencia (Zelanski \& Fisher, 2001).

Los expertos han encontrado que el color puede tener una influencia en los sentimientos y en las acciones de las personas, estos efectos están sujetos a factores personales, culturales y situacionales.

Como se observa en la Figura 12, los visitantes más jóvenes procedentes de Brasil, México y Argentina, asocian a Colombia con el café y la bandera nacional. Los visitantes chilenos, entre 29 y 39 años relacionan la imagen del país con la marca comercial Juan Valdez, las drogas, la música, la chiva y el sombrero vueltiao.

Los visitantes de origen peruano indicaron que las montañas, las aves, los ríos y las piedras preciosas representan $Y$ los mayores de 40 años, como en el caso de venezolanos, asocian a Colombia con las flores; y los estadounidenses con el fútbol, artistas y deportistas. Lo anterior refleja nuevamente un posicionamiento polarizado, en muchos campos, en diferentes símbolos. Esto motiva la necesidad de evaluar los atributos más cercanos con la imagen de Colombia que ayudarán a posicionar la estrategia de marca país.

Del total de la muestra, la mayoría de los visitantes $(97 \%)$ señalaron que en su última visita cambió la percepción del país. Predomina el interés por regresar a Colombia por parte de los extranjeros que ya lo visitaron. Este resultado demuestra que la experiencia del visitante en el país genera un cambio en la percepción favorable para el posicionamiento de Colombia. Y dada la experiencia positiva, el 98\% de los visitantes recomendaría a un amigo visitar a Colombia.

En el Análisis de Correspondencia aplicado al grupo de prospectos, se consideró la relación existente entre variables demográficas (edad y país de origen) con las variables asociadas a la imagen país de Colombia. Según el Test Chi Cuadrado hay una asociación significativa (ver Cuadro V). 
Figura 9. Análisis de correspondencia entre los aspectos negativos de Colombia y variables demográficas: país de origen y edad de los visitantes extranjeros

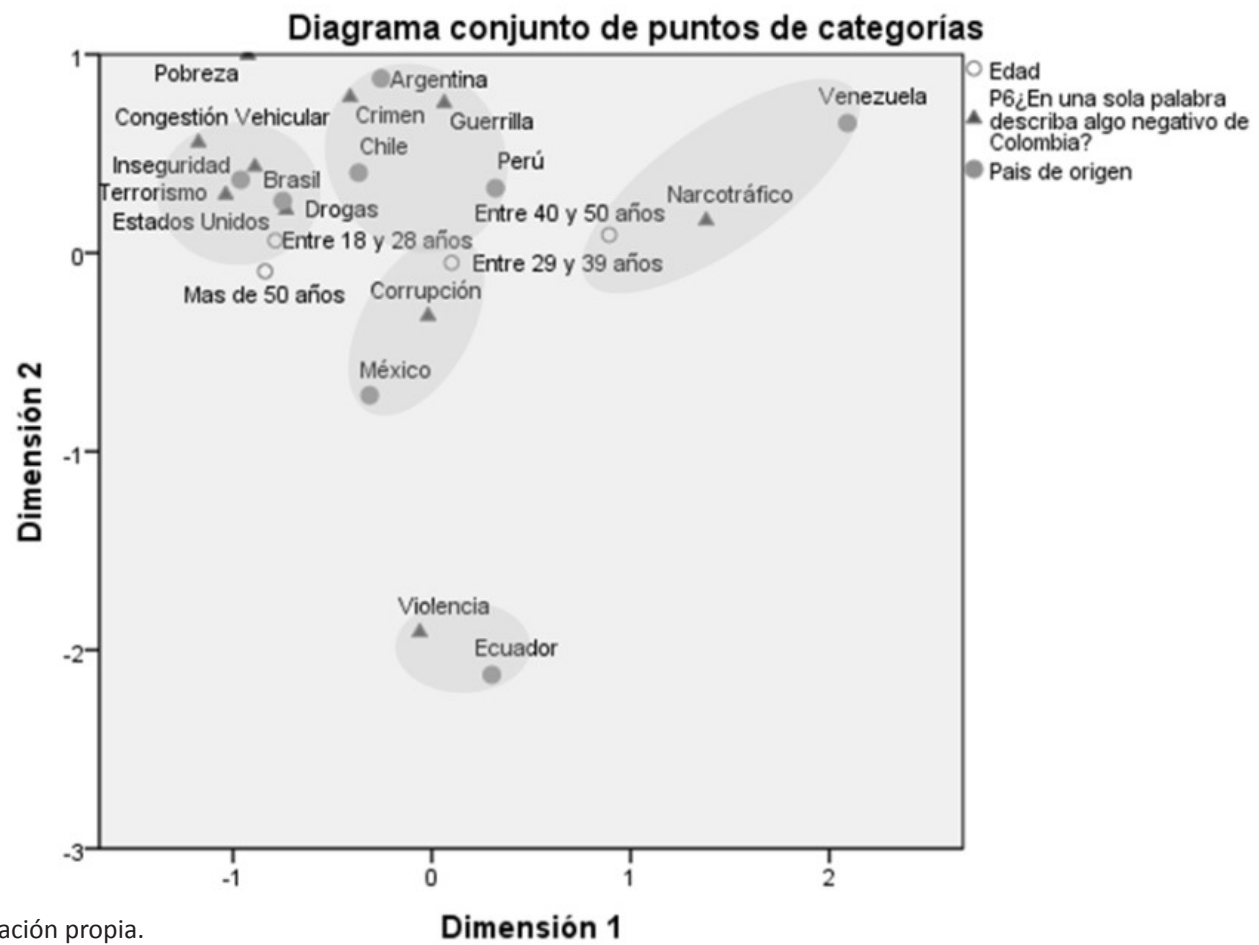

Figura 10. Análisis de correspondencia entre las características de los colombianos y país de origen de los visitantes extranjeros

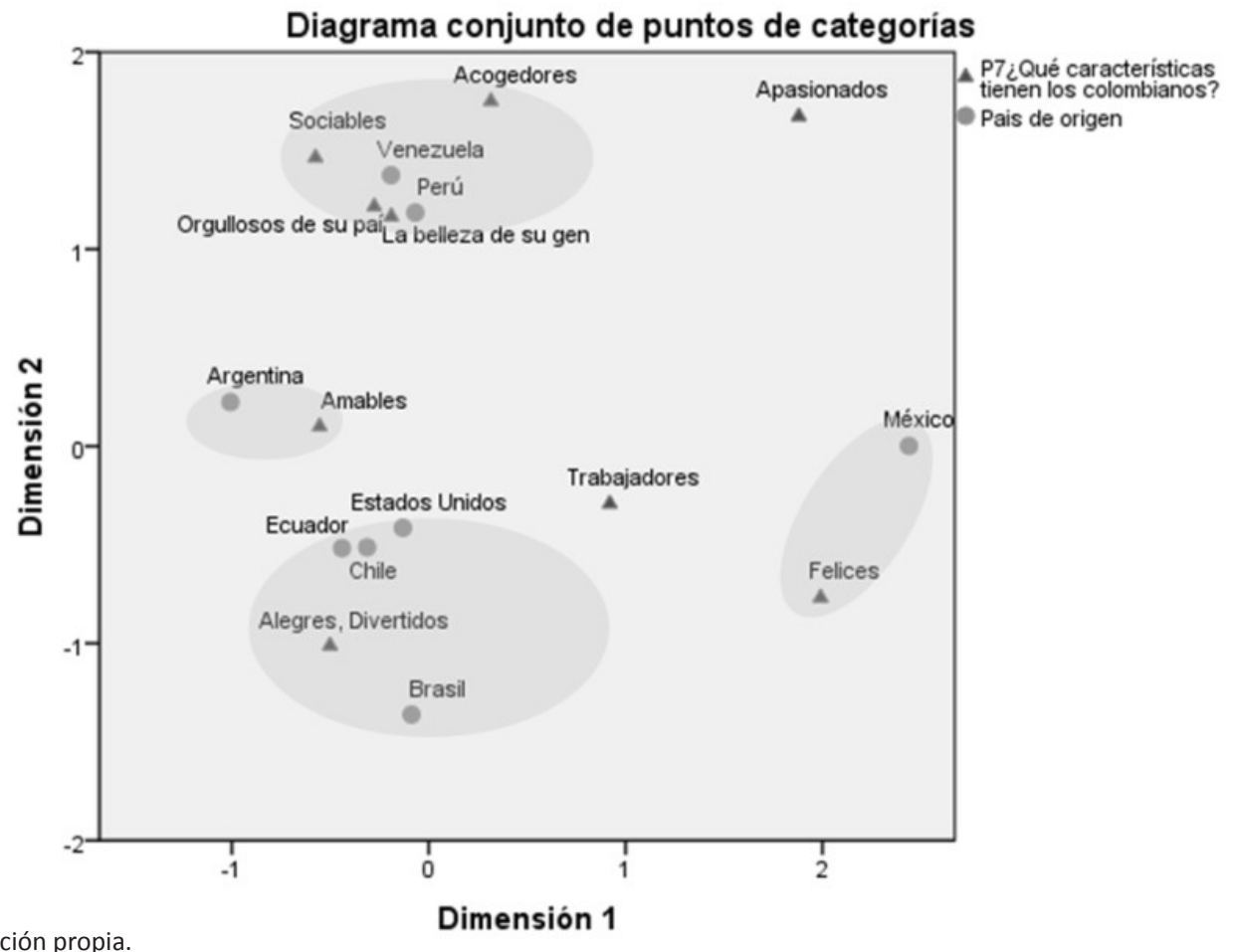

Fuente: elaboración propia.

Dimensión 1 
Cuadro IV. Test Chi Cuadrado de Asociación Simbólica de la imagen país de Colombia y variables demográficas de los visitantes

\begin{tabular}{|l|c|c|c|c|}
\hline \multirow{2}{*}{ Variables } & \multicolumn{2}{|c|}{ Edad } & \multicolumn{2}{c|}{ País de Origen } \\
\cline { 2 - 5 } & $\mathbf{X}^{2}$ & Sig. & $\mathbf{X}^{2}$ & Sig. \\
\hline ¿Para usted qué color tiene Colombia? & 24,8 &, 131 & 203,7 &, 000 \\
\hline ¿Para usted qué olor tiene Colombia? & 21,4 &, 045 & 189,5 &, 000 \\
\hline ¿Qué símbolo representa a Colombia? & 56,3 &, 007 & 333,8 &, 000 \\
\hline Cuando se menciona a Colombia ¿ंcon qué persona la asocia? & 100,2 &, 000 & 548,0 &, 000 \\
\hline
\end{tabular}

Fuente: elaboración propia.

Base: 760

Figura 11. Análisis de correspondencia entre el color que más se asocia a Colombia y el país de origen

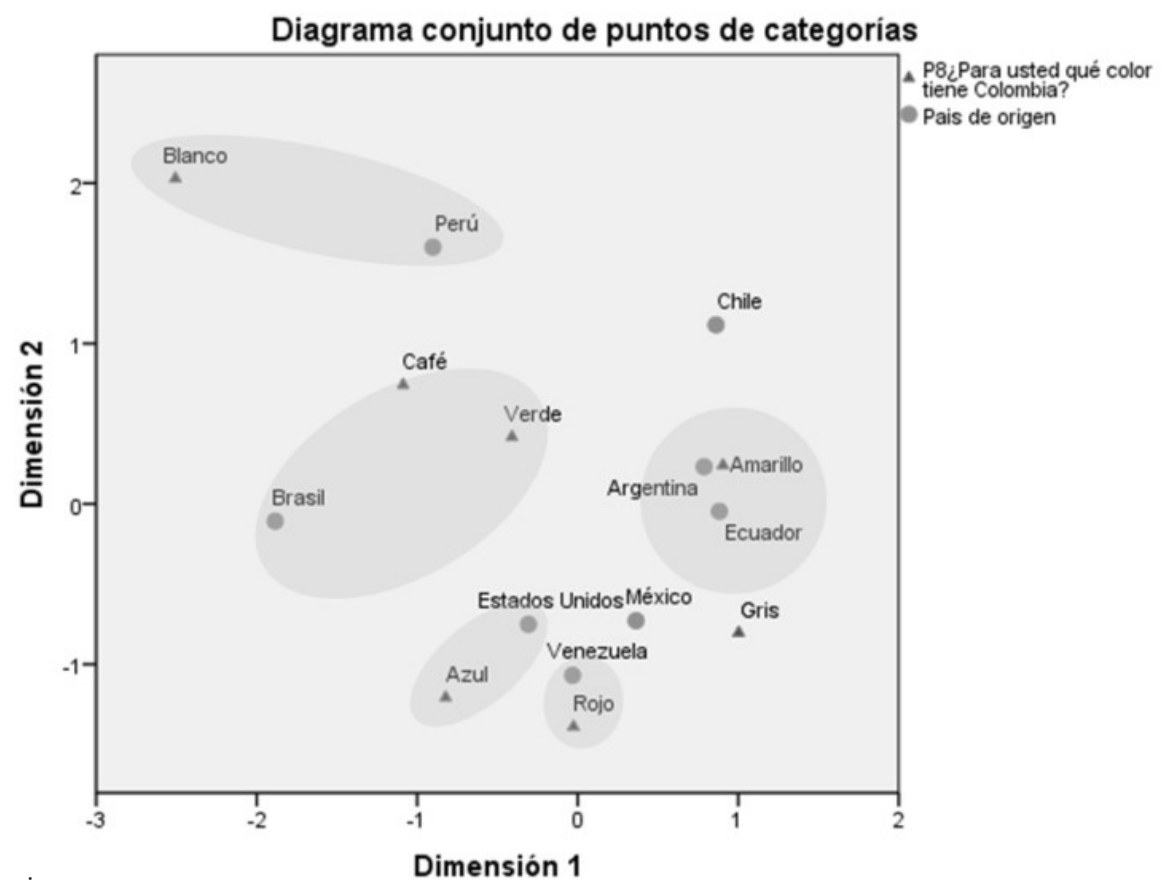

Fuente: elaboración propia.

Dimensión 1

Cuadro V. Test Chi Cuadrado de Imagen país de Colombia y variables demográficas de los prospectos

\begin{tabular}{|l|c|c|c|c|}
\hline \multirow{2}{*}{ Variables } & \multicolumn{2}{|c|}{ Edad } & \multicolumn{2}{c|}{ País de Origen } \\
\cline { 2 - 5 } & $\mathbf{X}^{2}$ & Sig. & $\mathbf{X}^{2}$ & \multicolumn{1}{c|}{ Sig. } \\
\hline $\begin{array}{l}\text { ¿Qué es lo primero que piensa cuándo oye la palabra } \\
\text { “Colombia”? }\end{array}$ & 47,558 &, 009 & 723,261 &, 000 \\
\hline $\begin{array}{l}\text { ¿En una sola palabra describa algo positivo de } \\
\text { Colombia? }\end{array}$ & 33,794 &, 429 & 695,536 &, 000 \\
\hline $\begin{array}{l}\text { ¿En una sola palabra describa algo negativo de } \\
\text { Colombia? }\end{array}$ & 33,238 &, 189 & 623,922 &, 000 \\
\hline ¿Qué características tienen los colombianos? & 41,835 &, 034 & 417,754 &, 000 \\
\hline
\end{tabular}

Fuente: elaboración propia.

Base: 784 
Figura 12.Análisis de correspondencia entre el símbolo que representa a Colombia y variables demográficas: país de origen y edad de los visitantes

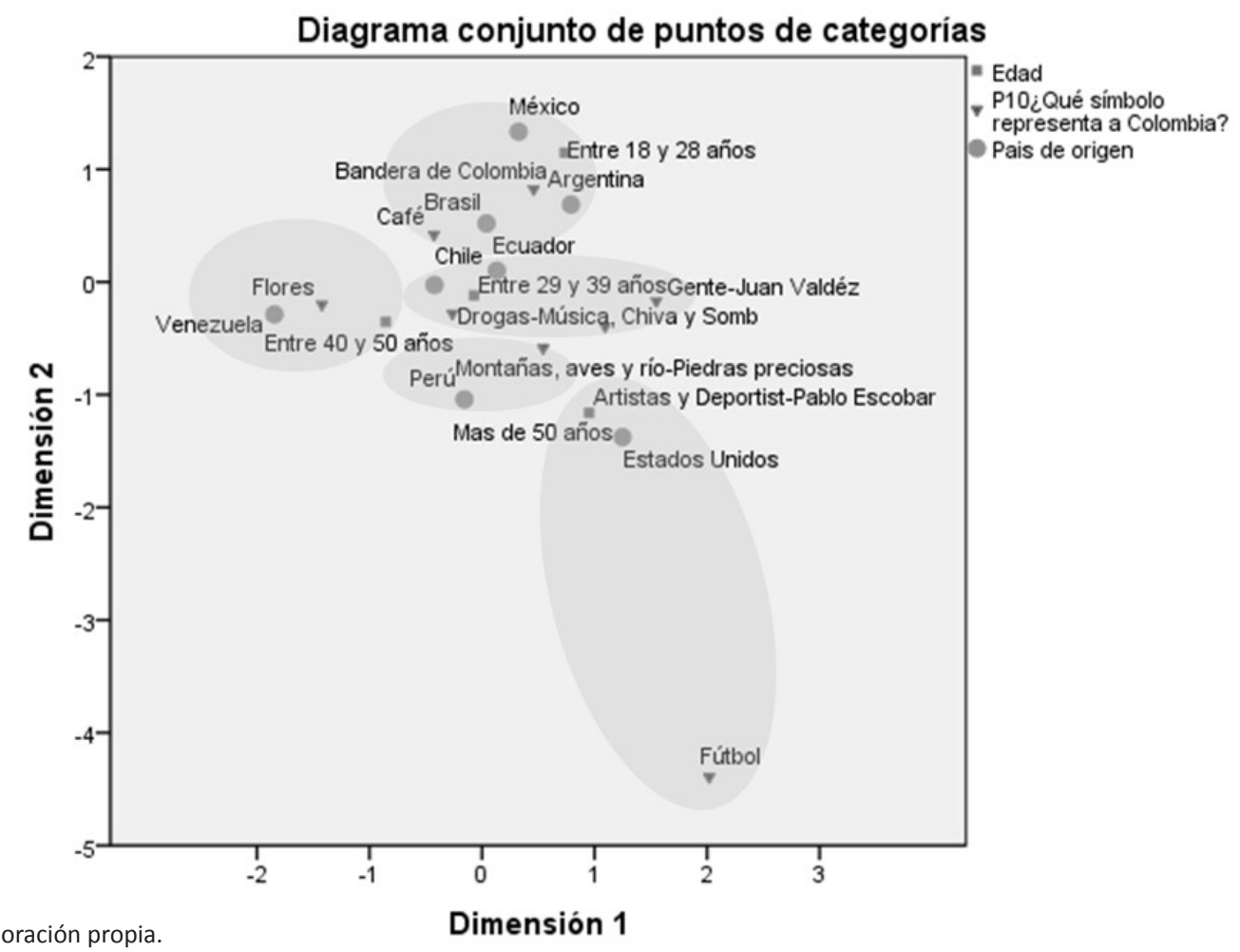

Fuente: elaboración propia.

Los extranjeros que aún no han visitado el país tienen impresiones claramente muy distintas. En la Figura 13, se puede observar que los prospectos procedentes de Argentina y Chile asocian la palabra Colombia con el café, las selvas, las montañas y las playas. Los venezolanos la asocian con arte, cultura y gastronomía. Los ecuatorianos relacionan a Colombia con turismo y desarrollo, los brasileros entre 40 y 50 años con drogas, terrorismo, inseguridad y corrupción.

Los estadounidenses y peruanos entre 29 y 39 años asocian la palabra Colombia con gente amable, acogedora, alegre y mujeres bellas.

El punto de vista positivo de la imagen de Colombia varía según el país de origen de los prospectos. Para los mexicanos y argentinos un aspecto positivo es el buen clima, para los venezolanos la gente amable y para los chilenos, la alegría del colombiano. Los prospectos procedentes de Brasil indicaron que la gastronomía es un aspecto positivo de Colombia. Para los estadounidenses que aún no han visitado a Colombia, las mujeres bellas y el café favorecen la imagen del país. En cuanto a los peruanos y ecuatorianos, el turismo es el aspecto positivo que más se asocia con
Colombia. Como se puede observar en la Figura 14, la imagen de Colombia es multidimensional. El país de origen de los prospectos es una dimensión que influye los puntos de vista positivos como negativos.

Los ecuatorianos que aún no han visitado a Colombia destacan que la violencia es un aspecto que afecta su imagen. Los peruanos relacionan a Colombia con el narcotráfico y la guerrilla. Los estadounidenses asocian al país con crimen. Los brasileros señalaron que los aspectos negativos que perciben son: la congestión vehicular, la pobreza y las drogas. Los mexicanos, chilenos y argentinos que no han viajado a Colombia, asocian su imagen con corrupción, inseguridad y terrorismo (ver Figura 15).

El reto para una marca país es consolidar una imagen positiva en el mercado. Las percepciones crean un proceso consciente y deliberado mensajes y experiencias acerca de un país, situación que debe transformarse en una experiencia distintiva, convincente, memorable y lo más gratificante posible. Para los brasileros, los colombianos se caracterizan por ser creyentes y felices. Para los ecuatorianos entre 40 y 50 años, los colombianos son trabajadores. 
Figura 13. Análisis de correspondencia entre lo que piensan los prospectos extranjeros cuando oyen la palabra Colombia y variables demográficas: país de origen y edad

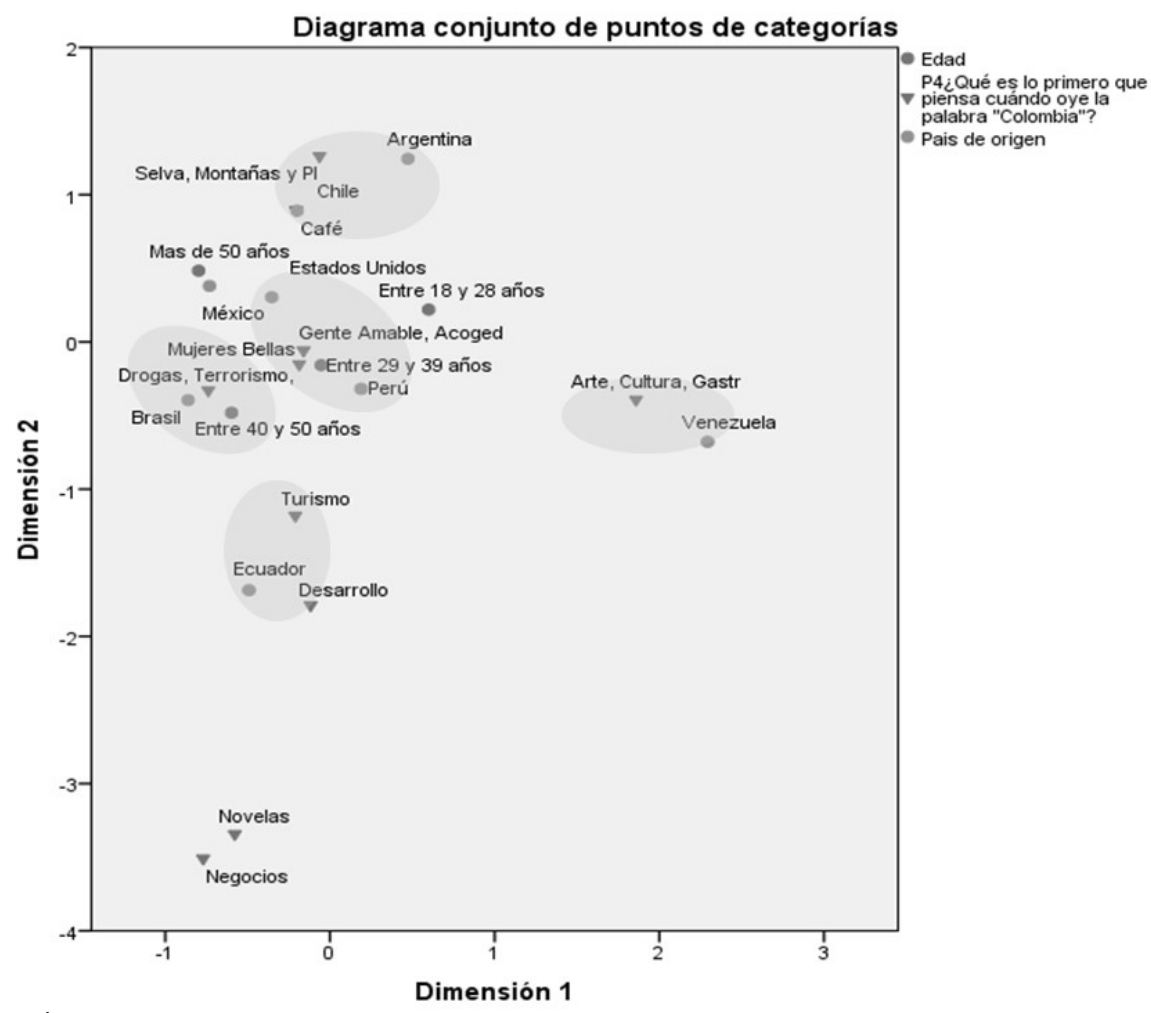

Fuente: elaboración propia.

Figura 14. Análisis de correspondencia entre los aspectos positivos de Colombia y variables demográficas: país de origen de los prospectos

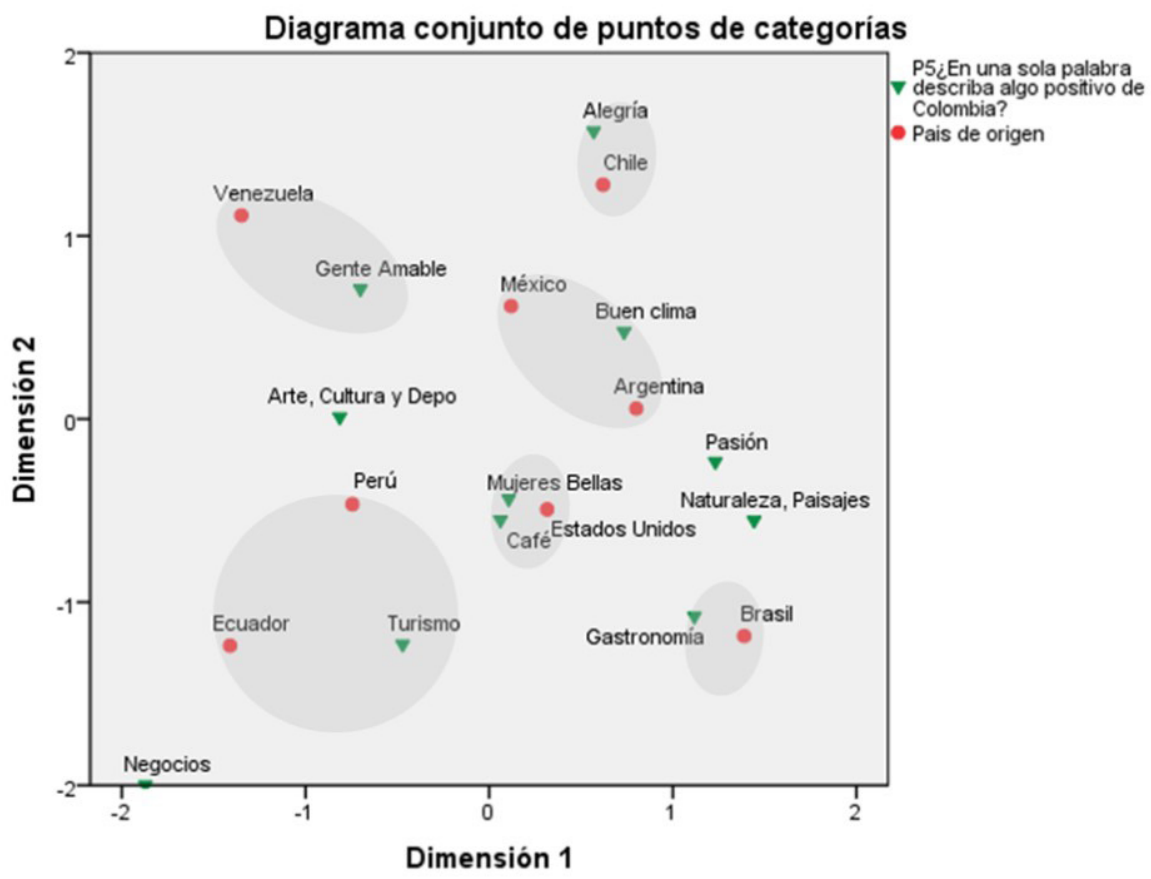

Fuente: elaboración propia.

Normalización principal por variable. 
Figura 15. Análisis de correspondencia entre los aspectos negativos de Colombia y variables demográficas: país de origen de los prospectos

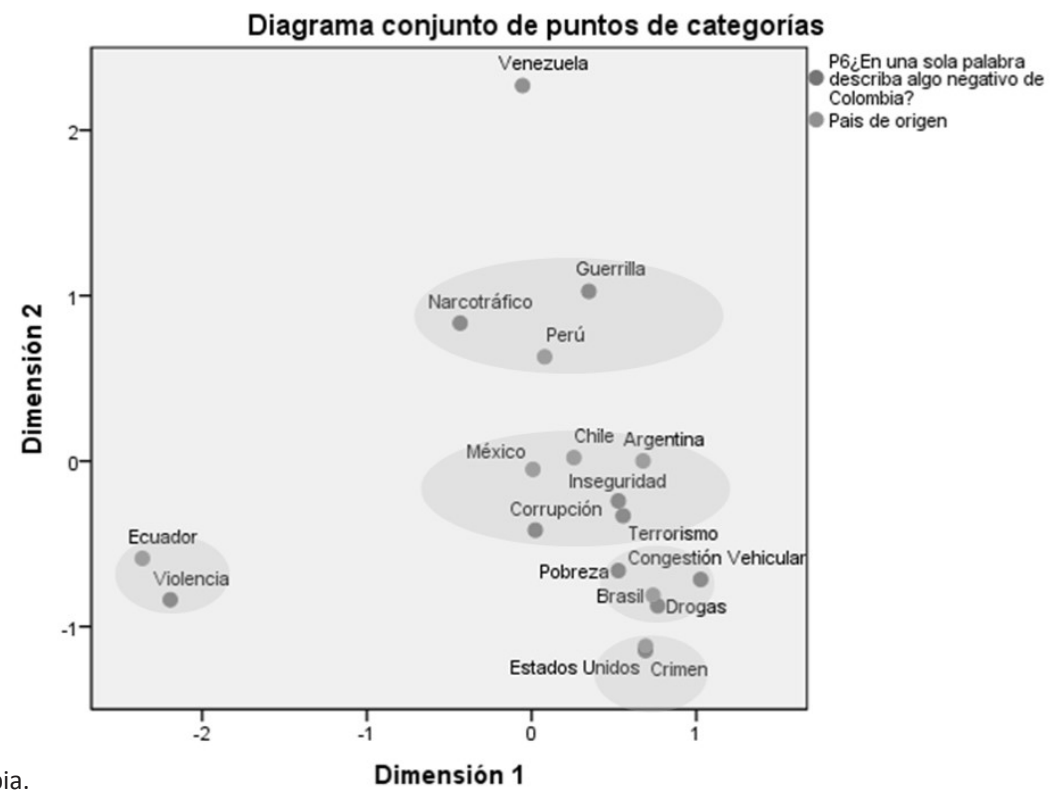

Fuente: elaboración propia.

Dimensión 1

De acuerdo a la Figura 16, los estadounidenses los consideran apasionados. Los mexicanos que aún no han visitado a Colombia, indican que su población se caracteriza por su amabilidad, la belleza de su gente y por sus sentimientos de orgullo hacia el país. Los chilenos, argentinos y peruanos coinciden en que el perfil del colombiano se caracteriza por ser sociable, alegre, divertido y acogedor.

En el Análisis de Correspondencia aplicado al grupo de prospectos se consideró la relación existente entre variables demográficas (edad y país de origen) con las variables vinculadas a la asociación simbólica de la imagen país de Colombia. Según el Test Chi Cuadrado hay una asociación significativa (ver Cuadro VI).

Los estadounidenses mayores de 50 años asocian a Colombia con las montañas, las aves y los ríos. Los chilenos entre 40 y 50 años, que no han viajado al país, lo asocian con la Bandera Nacional y con el narcotraficante Pablo Escobar. Los jóvenes adultos procedentes de Ecuador, Perú, México y Brasil, indicaron que los símbolos que representan a Colombia son el café, las drogas, la gente, los artistas y deportistas. Y los venezolanos, potencial visitante, consideran que las flores son el símbolo que se asocia a la imagen de Colombia (ver Figura 17).

Chilenos, peruanos, argentinos y mexicanos, entre 18 y 28 años, asocian a Colombia con el presidente
Juan Manuel Santos, la actriz Sofía Vergara y los cantantes Juanes y Shakira.

Para los ecuatorianos entre 40 y 50 años, consideran que los personajes que representan la imagen de Colombia son: la guerrilla de las FARC, el escritor Gabriel García Márquez, los amigos y familiares. Para los estadounidenses mayores de 50 años, relacionan a Colombia con el libertador Simón Bolivar y la marca comercial de Juan Valdez.

Los venezolanos indicaron que el deportista Pibe Valderrama y el expresidente Álvaro Uribe son las personas que representan la imagen de Colombia (ver Figura 18).

El $90 \%$ de las personas vinculadas al grupo de prospectos, señaló que compraría productos de origen colombiano. Este mismo grupo está interesado en visitar a Colombia (89\%).

En el estudio se aplicó un análisis clúster o por conglomerados para visitantes y prospectos, con la finalidad de examinar el conjunto de relaciones interdependientes según la importancia declarada que asignaron los entrevistados en sus respuestas. Se clasificaron los individuos en grupos relativamente homogéneos basados en el conjunto de las variables consideradas. Los individuos de un grupo son relativamente similares en términos de las variables planteadas y diferentes de los individuos de otros grupos. El método de aglomeración utilizado fue el método de Ward. 
Figura 16. Análisis de correspondencia entre las características que tienen los colombianos y variables demográficas: país de origen y edad de los prospectos

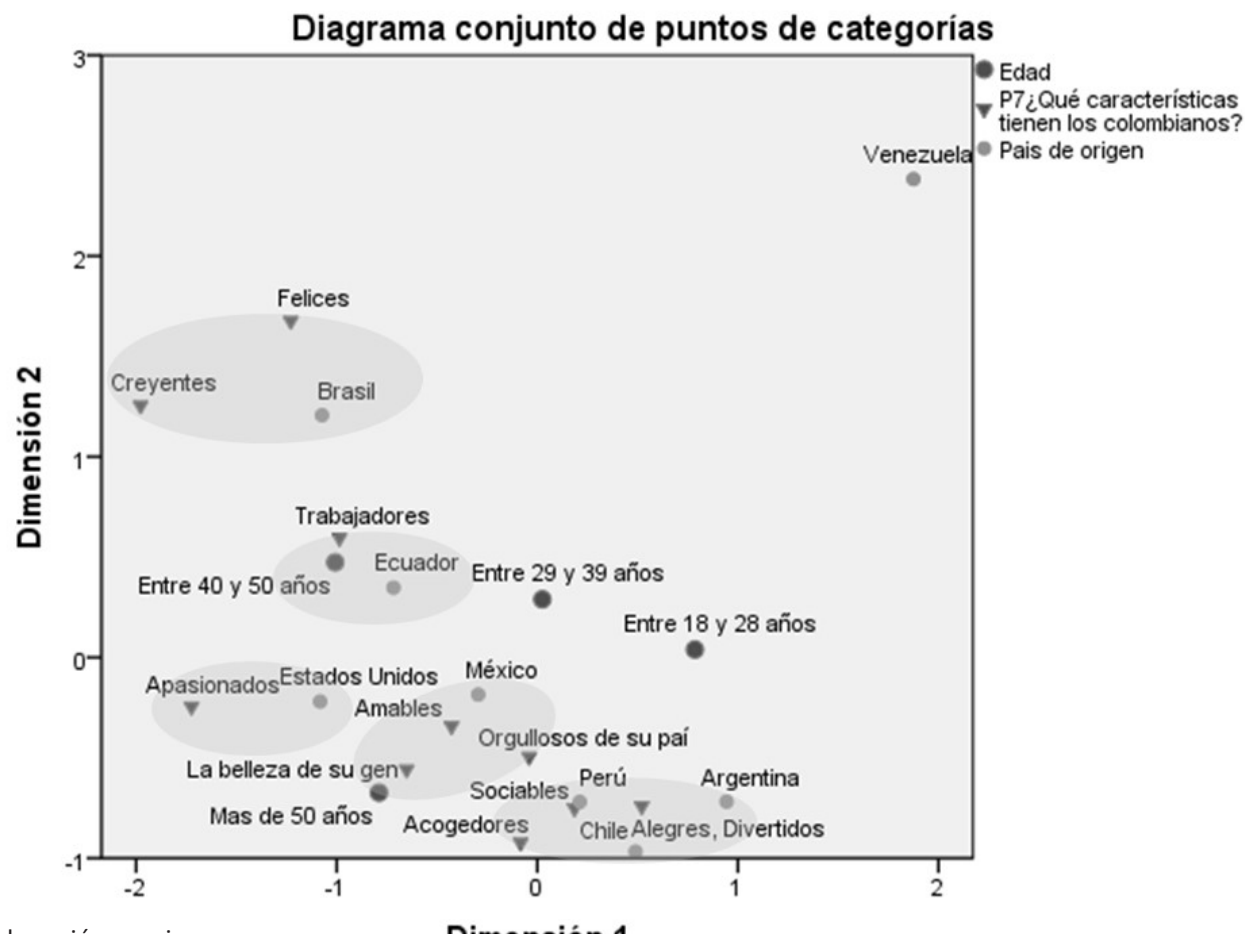

Fuente: elaboración propia.

\section{Dimensión 1}

Figura 17. Análisis de correspondencia entre el símbolo que representa a Colombia y variables demográficas: país de origen y edad de los prospectos

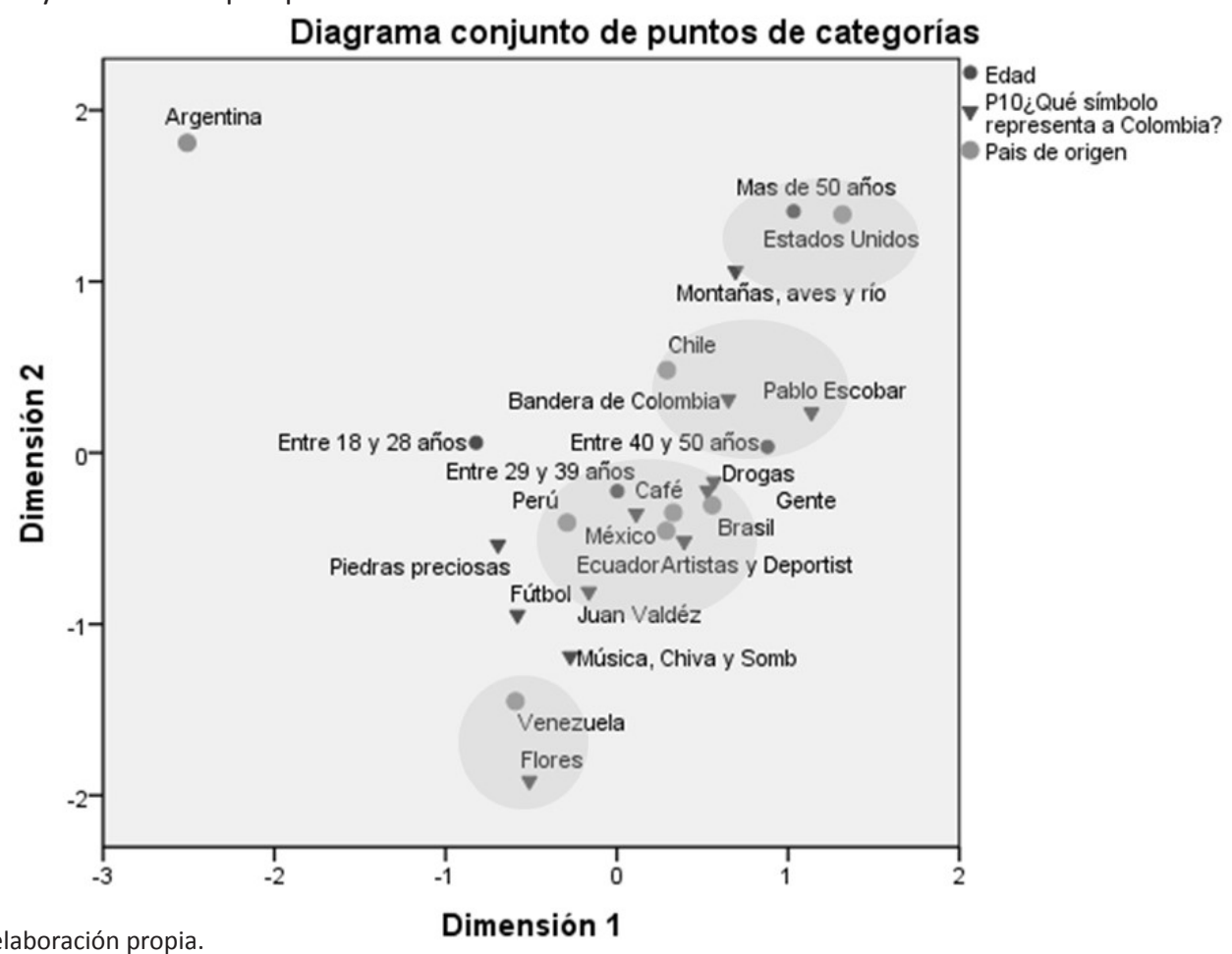

Fuente: elaboración propia.

\section{Dimensión 1}


Cuadro VI. Test Chi Cuadrado de Asociación Simbólica de la imagen país de Colombia y variables demográficas de los prospectos

\begin{tabular}{|c|c|c|c|c|}
\hline \multirow{2}{*}{ Variables } & \multicolumn{2}{|c|}{ Edad } & \multicolumn{2}{|c|}{ País de Origen } \\
\hline & $\mathbf{X}^{2}$ & Sig. & $\mathbf{X}^{2}$ & Sig. \\
\hline ¿Qué símbolo representa a Colombia? & 47,278 & 051 & 259,527 & 000 \\
\hline $\begin{array}{l}\text { Cuando se menciona a Colombia ¿qué ciudad se le viene a la } \\
\text { mente? }\end{array}$ & 37,546 & 015 & 371,154 & 000 \\
\hline Cuando se menciona a Colombia ¿̇con qué persona la asocia? & 75,133 & ,000 & 576,939 & 000 \\
\hline ¿Estaría interesado en visitar a Colombia? & 10,704 & 013 & 31,422 & 000 \\
\hline
\end{tabular}

Fuente: elaboración propia.

Base: 784

Figura 18. Análisis de correspondencia entre persona que asocia a Colombia y variables demográficas: país de origen y edad de los prospectos

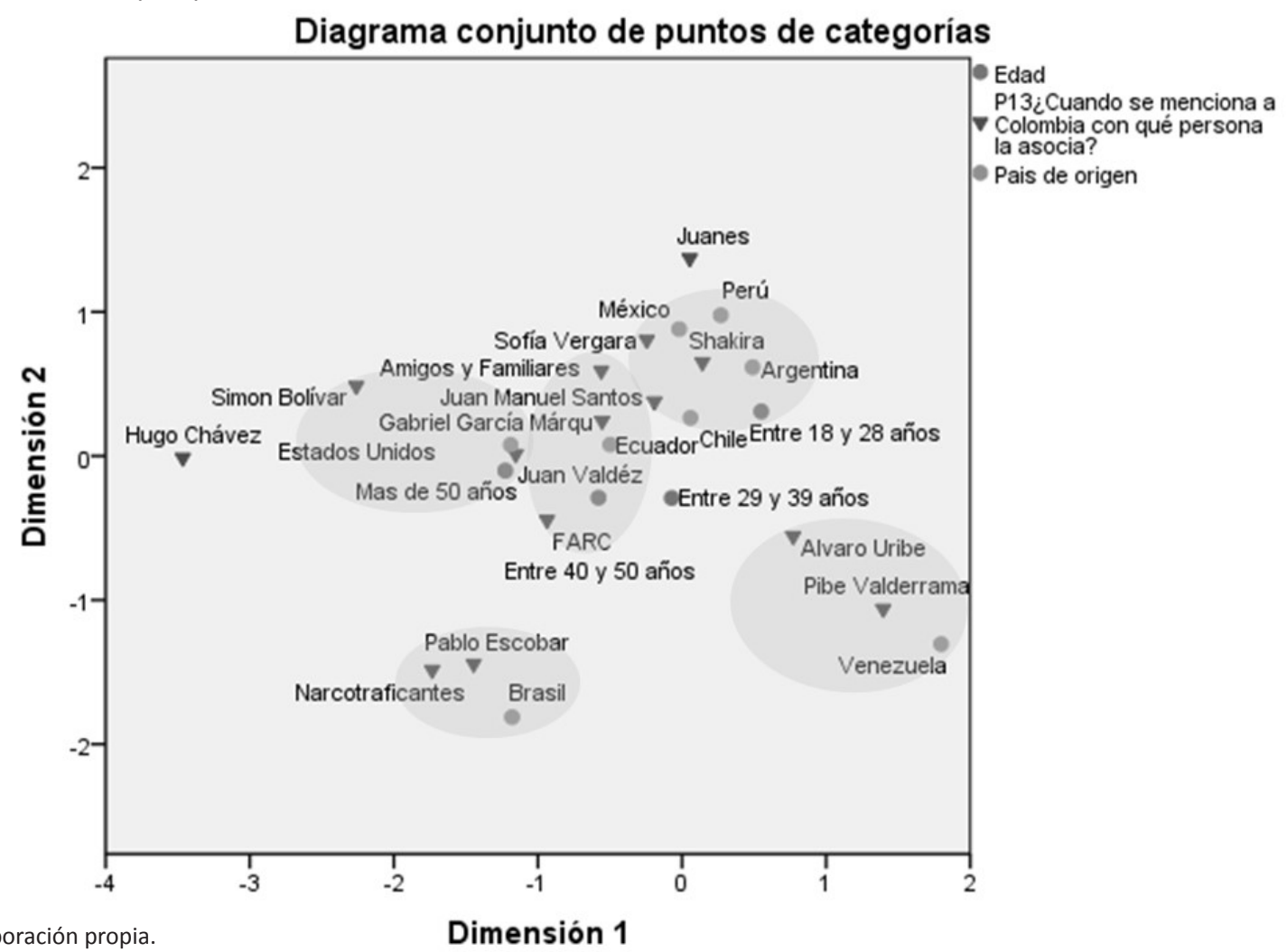

Los resultados indicaron que los visitantes podrían agruparse en tres segmentos. Las diferencias entre los segmentos fueron verificadas en forma estadística. Así, cada segmento contiene entrevistados relativamente homogéneos en cuanto a sus criterios de elección. A continuación se estimó por separado un modelo de elección para visitantes y prospectos.

El análisis clúster aplicado a visitantes se detectó tres segmentos: expectantes, recurrentes y fronteri- zos (ver Figura 19). Y el mismo análisis aplicado a prospectos, se identificaron dos segmentos: compradores potenciales y latentes (ver Figura 20).

Según el Dendograma de Clasificación de visitantes que participaron en el estudio, se puede apreciar tres clases o grupos. La clase 1 formada por 504 visitantes, la clase 2 por 168 visitantes y la tres por 88 visitantes. 
Figura 19. Dendograma del análisis clúster de los extranjeros que han visitado a Colombia

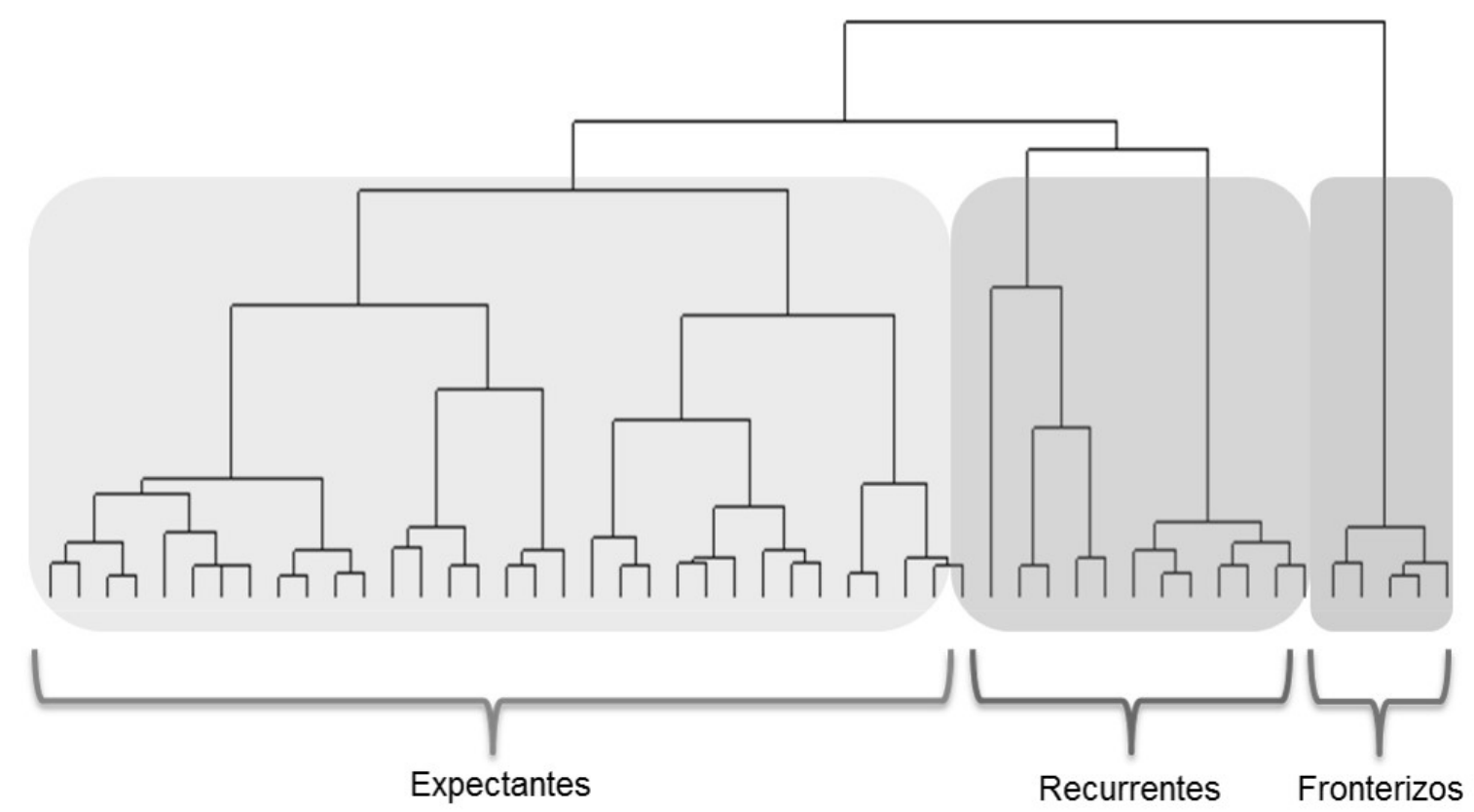

Fuente: elaboración propia.

Una vez elegido el número de clases se obtiene la partición y los indicadores de la homogeneidad de las clases obtenidas, La clase más homogénea y pequeña es la clase 3 (inercia 0,0732), la clase 1 la más heterogénea (inercia de 0,8771 ) y la más grande de las tres clases (ver Cuadro VII).
En el cuadro VIII se pueden observar las coordenadas de las clases sobre los ejes factoriales y sus valores- test. Las clases se pueden interpretar al igual que la posición de los individuos sobre el primer plano factorial.

Cuadro VII. Descomposición de la inercia

\begin{tabular}{|l|c|c|c|}
\hline Inercias & Inercias & Efectivos & Distancias \\
\hline Inter-clases & 0,2139 & & \\
\hline Intra-clases & & & \\
\hline Clase 1 & 0,8771 & 504 & 0,0470 \\
\hline Clase 2 & 0,3776 & 168 & 0,3593 \\
\hline Clase 3 & 0,0732 & 88 & 0,8926 \\
\hline Total & 1,5418 & & \\
\hline
\end{tabular}

Fuente: elaboración propia.

Cuadro VIII. Coordenadas y valores- test sobre los ejes factoriales

\begin{tabular}{|l|c|c|c|c|}
\hline \multirow{2}{*}{ Clases } & \multicolumn{2}{|c|}{ Valores test } & \multicolumn{2}{c|}{ Coordenadas } \\
\cline { 2 - 5 } & Eje 1 & Eje2 & Eje 1 & Eje2 \\
\hline Clase 1 & $-6,2$ & $-2,4$ & $-0,09$ & $-0,03$ \\
\hline Clase 2 & $-11,2$ & 5,3 & $-0,29$ & 0,13 \\
\hline Clase 3 & 21,1 & $-3,0$ & 0,73 & $-0,10$ \\
\hline
\end{tabular}

Fuente: elaboración propia. 
Las características del primer clúster de visitantes estadounidenses se agrupa en este estudio bajo la denominación de Visitantes Expectantes: son visitantes procedentes de Brasil, Chile, Argentina y México. Les gustaría vivir en Brasil, Perú y Colombia. Para este grupo, Pablo Escobar, el Pibe Valderrama y Shakira son los personajes que más representan a Colombia en mercados internacionales. En su visita lo que más le gustó fue la cultura y la ciudad de Cartagena. Lo que menos les gustó fue la suciedad, los vendedores ambulantes y la inseguridad en el país. Un aspecto negativo que se percibe de Colombia es la inseguridad, la guerrilla y las drogas. Lo primero que piensan cuando oyen la palabra Colombia es en la selva, montañas, playas, arte cultura y gastronomía. Para los visitantes de este segmento, la amabilidad y la alegría de los colombianos son los aspectos positivos que mejor se asocian con la imagen del país. Para este grupo, los colombianos se caracterizan por ser alegres, acogedores, divertidos y felices. Para ellos el color de Colombia es el amarillo y el aroma es a café y flores.

El segundo clúster corresponde a los Visitantes $\boldsymbol{R e}$ currentes Son visitantes frecuentes, procedentes de Ecuador y Estados Unidos. Les gustaría vivir en Chile. Cuando se menciona a Colombia la asocian con amigos y familiares. En su visita lo que más le gustó fue la cultura y lo que menos les gustó fue el clima. Al escuchar la palabra Colombia la relacionan con negocios, drogas y terrorismo. La pasión y los negocios son aspectos positivos de Colombia. Sin embargo, consideran que la violencia y el crimen son aspectos negativos del país. Para este grupo de visitantes, los colombianos se caracterizan por ser trabajadores. Asocian a Colombia con el color rojo y verde. Los visitantes estadounidenses y ecuatorianos relacionan a Colombia con el aroma a flores.

El tercer grupo conformado por los Visitantes Fronterizos. Venezolanos, entre 40 y 50 años que les gustaría vivir en su país natal y en Colombia. Para estos visitantes, el café y las flores simbolizan a Colombia. Los amigos, familiares y el expresidente Álvaro Uribe son las personas con las que más asocian la imagen de Colombia. En su visita lo que más les gustó fue la gastronomía y los lugares turísticos.

Lo que menos gustó fue la pobreza y el tráfico. Al segmento de estudio, les gustaría visitar Argentina y Brasil. La imagen de Colombia está altamente asociada a las características de sus habitantes. Para estos visitantes, los colombianos son acogedores, apasionados y sociables. El color con el que más asocian a Colombia es el azul, porque representa la naturaleza y sus paisajes. En este sentido, relacionan a Colombia con el aroma a la naturaleza y a su gastronomía. Un aspecto negativo del país es el narcotráfico. Para este grupo, la naturaleza, paisajes y la amabilidad de la gente son tres aspectos positivos con los que se relaciona la imagen país de Colombia.

La Figura 20 expone el Dendograma de Clasificación de prospectos (visitantes potenciales) que participaron en el estudio, se puede apreciar dos clases o grupos.

Figura 20. Dendograma del análisis clúster de los prospectos

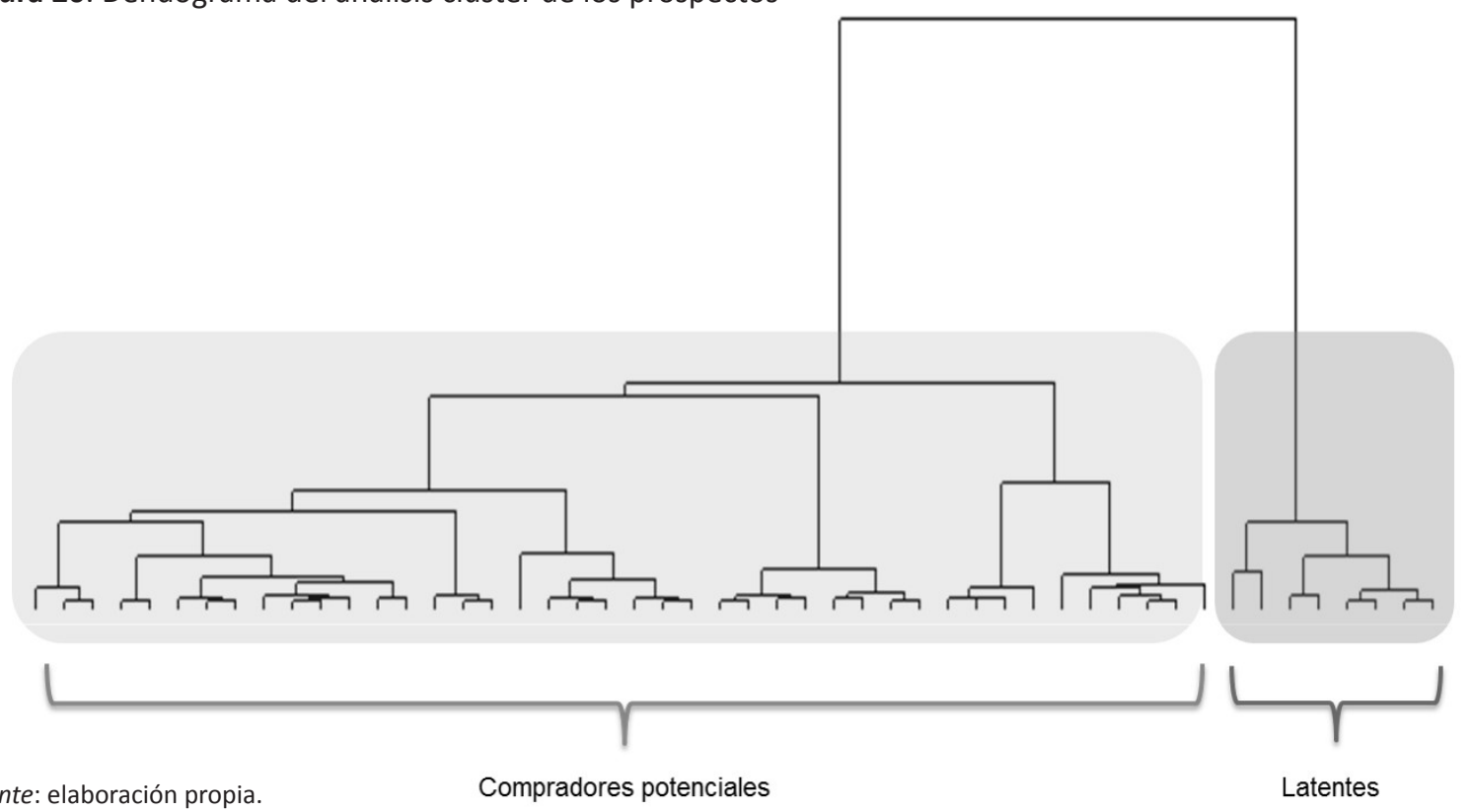


Una vez elegido el número de clases se obtiene la partición y los indicadores de la homogeneidad de las clases obtenidas. La clase más homogénea y pequeña es la clase 2 (inercia 0,1702) con 95 personas, la clase 1 la más heterogénea (inercia de 0,8771) y la más grande de las dos clases (689 personas) (ver Cuadro IX).

En el cuadro $X$ se pueden observar las coordenadas de las clases sobre los ejes factoriales y sus valorestest. Las clases se pueden interpretar al igual que la posición de los individuos sobre el primer plano factorial.

En el estudio los prospectos cobran relevancia porque sus apreciaciones distan de una experiencia de visita. En su imaginario colectivo, los prospectos han creado una propia imagen país de Colombia, cercana o ajena a los visitantes, este grupo se convierte en objetivo de análisis, porque sobre ellos es que se deben redireccionar también las estrategias que se formulen desde marca país.

Según el análisis realizado, del grupo de prospectos se generan dos nuevos segmentos. El primer clúster denominado Compradores potenciales. Son extranjeros que les gustaría vivir en Brasil, Ecuador, Perú y Colombia. Para ellos la bandera de Colombia, las montañas, aves, ríos, el café la música, la chiva y el sombrero vueltiao son los símbolos que más representan al país. El café, los textiles y el turismo son los sectores productivos que se asocian al país. La palabra Colombia tiene una percepción polarizada, la relacionan con las drogas y el terrorismo; pero simultáneamente la asocian con el café, la selva, las montañas, las playas, la gente amable y acogedora. Cuando se menciona a Colombia, lo asocian con ciudades como Medellín, Barranquilla, Bogotá y Cartagena. Los amigos, familiares; y artistas como Gabriel García Márquez, Juanes y Sofía Vergara son los personajes que identifican a Colombia. Para este grupo, los colombianos se caracterizan por ser: alegres, divertidos, amables, trabajadores y sociables. El primer clúster, resultado del análisis, desearía visitar en América del Sur a Brasil y Perú. Estarían interesados en comprar productos colombianos, y en visitar al país.

El segundo clúster está conformado por los Latentes. Son venezolanos que no han visitado a Colombia. Prefieren permanecer en su país de origen en lugar a de visitar Colombia. Para este segmento, las flores, el café, la música, la chiva y el sombrero vueltiao son los símbolos más representativos del país. Asocian al deportista Pibe Valderrama y al expresidente Álvaro Uribe con la imagen de Colombia. El arte, la cultura y la gastronomía son los aspectos que primero recuerdan cuando oyen la palabra Colombia. La amabilidad de la gente, el arte, la cultura y el deporte, son cuatro aspectos positivos del país. Desde el punto de vista negativo, relacionan a la guerrilla y el narcotráfico con Colombia. Las ciudades de Cartagena y Barranquilla son las que más asocian con Colombia. Este grupo de visitantes potenciales, les gustaría viajar a Perú. En los resultados del estudio, el grupo indicó que no compraría productos de origen colombiano.

Cuadro IX. Descomposición de la inercia

\begin{tabular}{|l|c|c|c|}
\hline Inercias & Inercias & Efectivos & Distancias \\
\hline Inter-clases & 0,3547 & & \\
\hline Intra-clases & & & \\
\hline Clase 1 & 1,3094 & 689 & 0,0489 \\
\hline Clase 2 & 0,1702 & 95 & 2,5727 \\
\hline Total & 1,8343 & & \\
\hline
\end{tabular}

Fuente: elaboración propia.

Cuadro X. Coordenadas y valores- test sobre los ejes factoriales

\begin{tabular}{|l|c|c|c|c|}
\hline \multirow{2}{*}{ Clases } & \multicolumn{2}{|c|}{ Valores test } & \multicolumn{2}{c|}{ Coordenadas } \\
\cline { 2 - 5 } & Eje 1 & Eje2 & Eje 1 & Eje2 \\
\hline Clase 1 & $-26,2$ & $-1,9$ & $-0,22$ & $-0,01$ \\
\hline Clase 2 & 26,2 & 1,9 & 1,60 & 0,09 \\
\hline
\end{tabular}

Fuente: elaboración propia. 
Las redes bayesianas que se aplicaron al estudio, muestran cómo un conjunto de variables establecen relaciones entre ellas. En una red bayesiana cada variable es tiene su funccion de densidad condicional en las variables que impactan e influyen sobre esta última. En el estudio aplicado se encontraron relaciones entre algunas variables

Como se puede observar en la Figura 21, la variable sobre el país dónde le gustaría vivir a los extranjeros en América del Sur está condicionada por el lugar de procedencia y los aspectos positivos asociados a la imagen país. Existe una relación de dependencia en la variable de País que los extranjeros quieren visitar y el país que los extranjeros quieren vivir. Es decir, la elección de un destino para vivir, impacta en la elección de un destino para visitar. Los extranjeros eligen a Brasil como el destino para vivir y visitar. Los aspectos positivos impactan sobre los aspectos negativos de la imagen país de Colombia y sobre el país que los extranjeros prefieren para vivir.

Figura 21. Red Bayesiana 1

Fuente: elaboración propia.

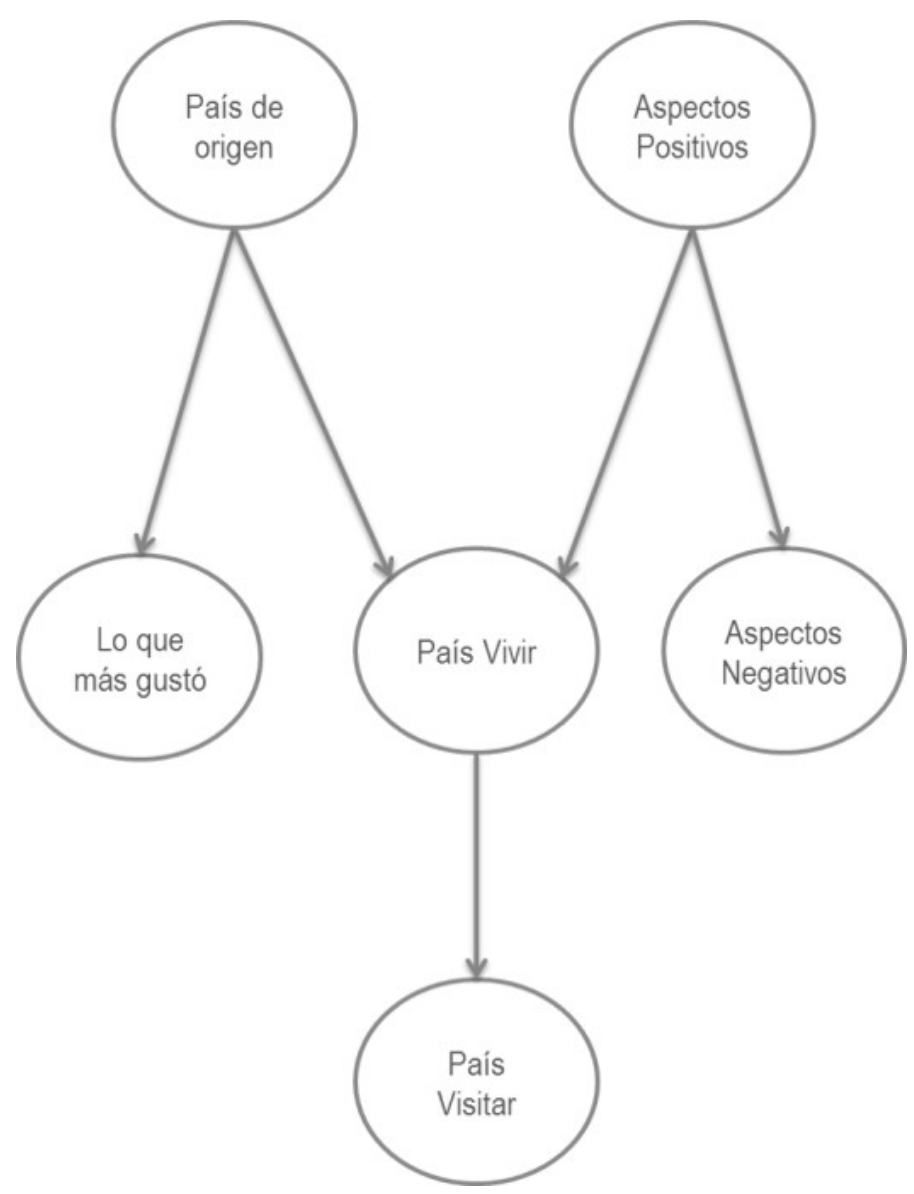

En la Figura 22 muestra como los árboles obtenidos establecen una dependencia directa con respecto a la variable dependiente, en este caso el Color. Es decir, el color con el que se percibe un país es generado por la asociación de la imagen del país con un producto y con una ciudad. Cuando los extranjeros asocian a Colombia con un producto, esta percepción, está sujeta a dos variables: el país de origen y lo primero que piensa cuando oye la palabra "Colombia". La red bayesiana que se presenta en la Figura 22, expone cómo la variable clase, es decir, la variable sobre el cambio de opinión de los extranjeros después de una visita a un país, condiciona la variable relacionada con que lo visitaría nuevamente. Tiene sentido esta relación, dado que si se mejora la opinión que tienen los extranjeros sobre Colombia, ellos estarían dispuestos a visitarlo nuevamente.

Cuando un extranjero visita nuevamente un lugar, implica que lo recomendarían a otros extranjeros que aún no lo han visitado. La variable sobre lo que más gustó de Colombia durante su visita y la variable sobre el país de América del Sur que les gustaría vivir, ambas impactan el nodo del país de origen de los extranjeros. 
Figura 22. Red Bayesiana 2

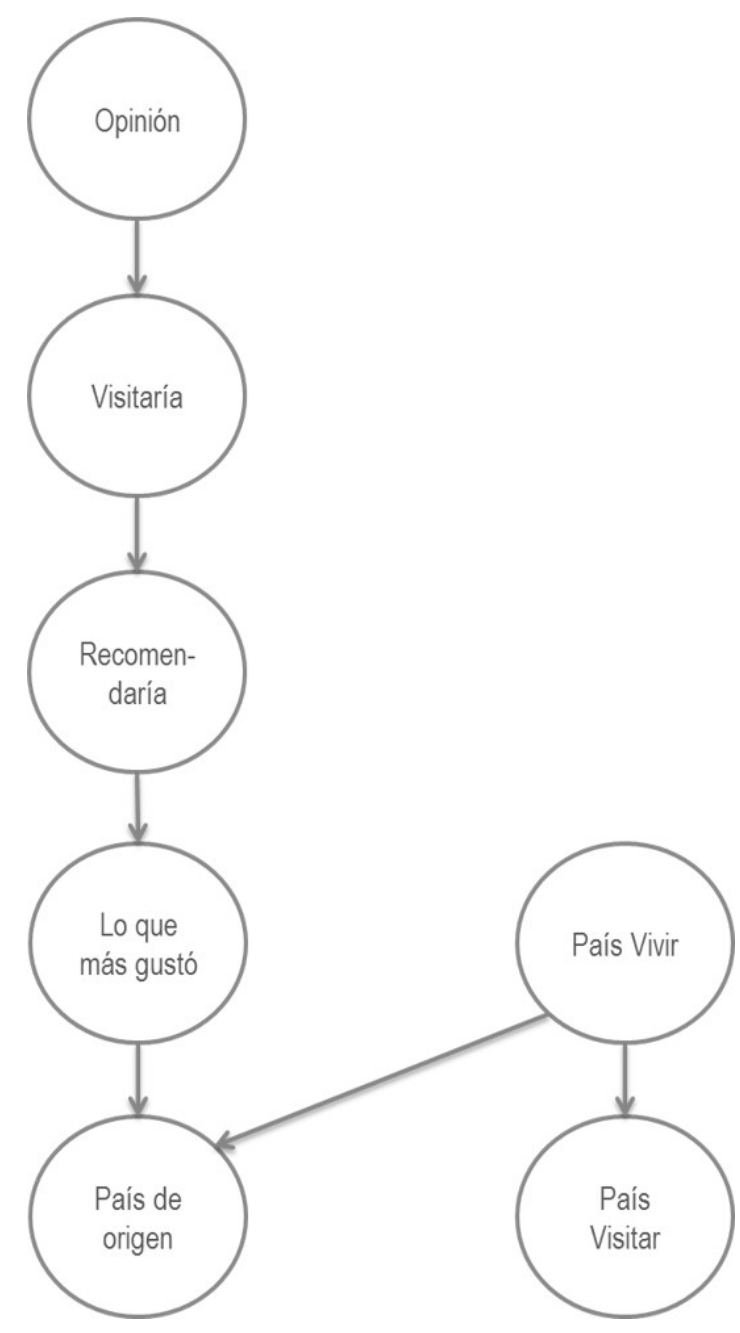

En la Figura 23, comprende la Red Bayesiana 3, en la cual se puede observar cómo las variables relacionadas con el número de veces que ha visitado al país, lo primero que piensan los extranjeros cuando oyen la palabra "Colombia; y el país de origen de los extranjeros condicionan el tipo de producto con que los extranjeros asocian al país. Para los extranjeros decidir si visitarían de nuevo un lugar, depende de la opinión que tengan del mismo y la familiaridad con el producto (made in).

Lo que más gusta de un país está condicionado por las recomendaciones de los extranjeros, el símbolo que representa al país y su procedencia. La variable sobre el símbolo que mejor representa a un país depende del olor. El olor es una señal de identidad. En el caso de una estrategia de marca país, se debe pensar en el odotipo, el cual consiste en una forma aromática que se registra como un elemento en la identidad de la marca territorio.
Como se puede observar, en el grafo, el olor asociado a la imagen de un país y el país donde prefieren vivir los extranjeros, son el resultado de los aspectos positivos que se tiene de un país. En el estudio, Colombia es asociada al aroma del café, la gastronomía y la naturaleza. Las anteriores asociaciones de originan de los aspectos positivos que tienen los extranjeros sobre Colombia, entre los cuales mencionaron la naturaleza, los paisajes, el turismo, la gastronomía.

En la Figura 24, la variable de país de origen de los extranjeros condiciona cuatro variables: el producto asociado a un país, la intención de compra de productos internacionales, el país preferido para vivir y los aspectos que más gustaron durante su visita. El producto asociado a un país está condicionado por el país de origen del extranjero, las veces que ha visitado el destino y la recordación que tienes sobre la imagen de un lugar. 
Figura 23. Red Bayesiana 3

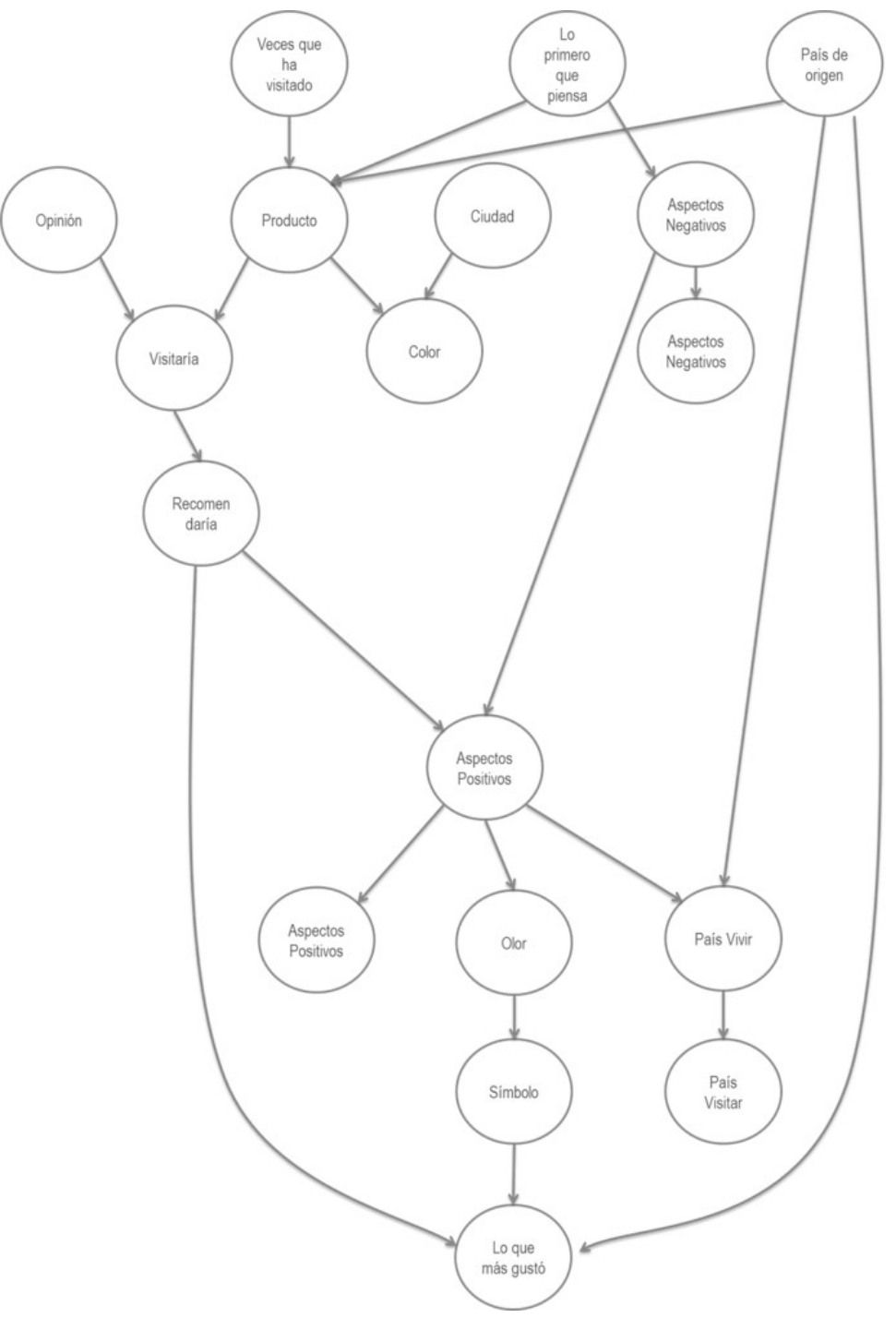

Fuente: elaboración propia.

Conforme a los resultados de la investigación, Colombia tiene un posicionamiento multidimensional, positivo y negativo. En lo positivo, una imagen país centrada en el café y las flores, y en lo negativo, manteniendo una asociación histórica con el narcotráfico. La tarea a seguir para la marca país de Colombia es concentrase en tres propósitos fundamentales:

a. Posicionar la imagen de Colombia de forma diferencial y preferencial en la mente de los visitantes y prospectos.

b. Bloquear a los competidores la posibilidad de vincularse a la misma idea o concepto.

c. Hacer los cambios internos que sean necesarios para que la idea/concepto sea creíble y sostenible a largo plazo.

\section{CONCLUSIONES}

La imagen es un estado mental compuesto por una red de asociaciones afectivas y cognitivas que se conectan cuando se piensa en un país. La percepción se construye desde tres fuentes: a) la experiencia, b) los medios y líderes de opinión, y c) los grupos de referencia. Los consumidores construyen una percepción global de un país en función de la experiencia positiva o negativa previa con la comercialización de sus productos.

Las imágenes que se tienen sobre un país generalmente están relacionadas con la manera en que se perciben como destinos turísticos, lugares para invertir o para comprar las marcas preferidas por los clientes. De acuerdo a los resultados encontrados, la percepción que tienen los estadounidenses sobre Co- 
Figura 24. Red Bayesiana 4

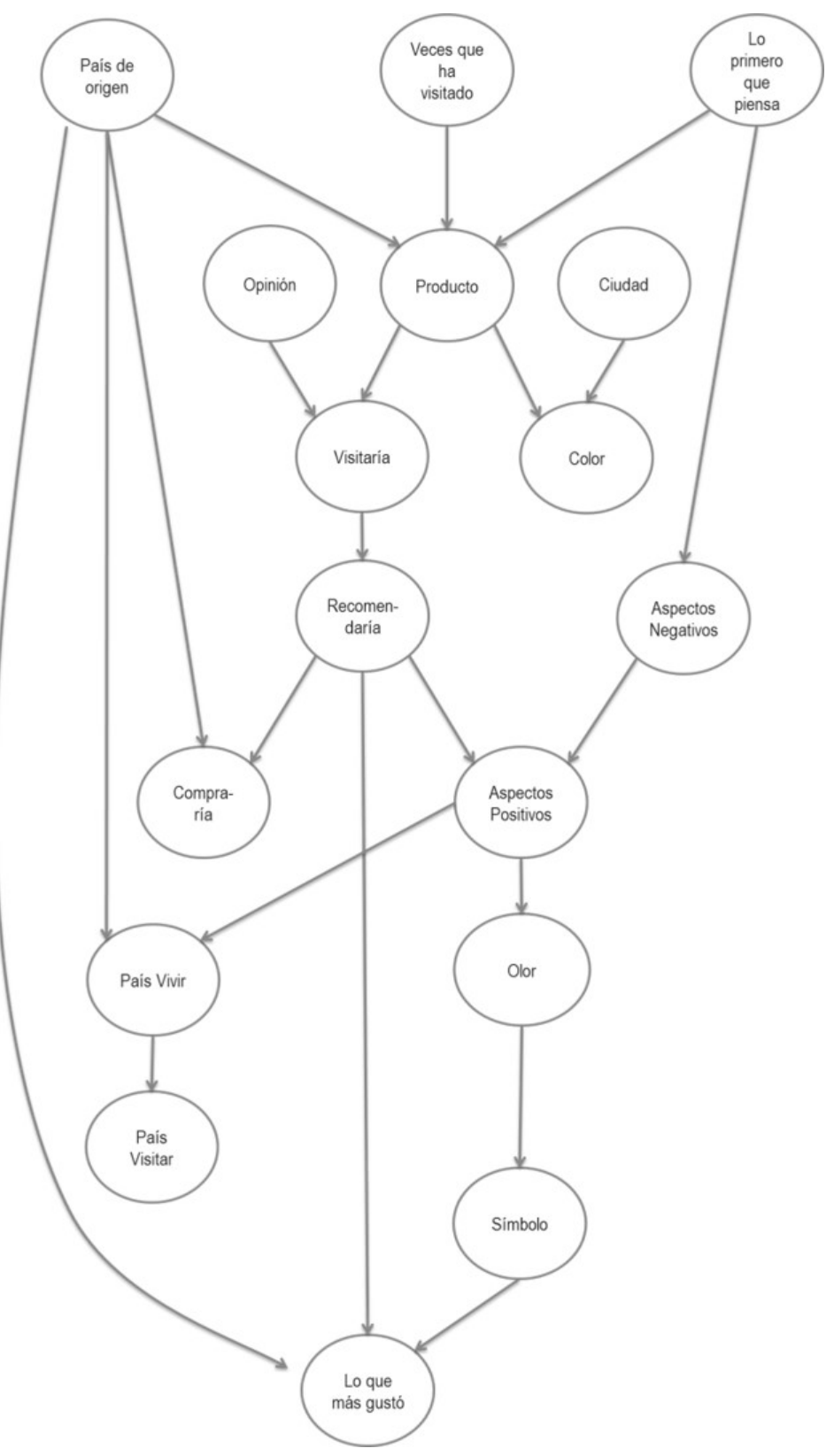

lombia cobra relevancia por ser el principal emisor de visitantes hacia el país. La experiencia del visitante estadounidense demuestra cómo su percepción difiere del no visitante. El estadounidense que ha visitado a Colombia, quiere regresar al país, y lo asocia con mujeres bellas y naturaleza. Sin embargo, coincide con la percepción del no visitante, al asociar a Colombia también con las drogas, el terrorismo y el café.

Aplicando el análisis de correspondencia hacia visitantes, existe asociación entre símbolos de la imagen país con variables demográficas. Especialmente la variable de edad, muestra a través de cuatro categorías

la diferencia de percepciones frente a colores, olores, características del colombiano y personas con las que se asocia al país.

Una imagen país percibida positiva es importante para Colombia. Si la imagen es positiva, los visitantes exponen todo lo que viven de manera positiva, pero si la imagen percibida es negativa, esto no solo le puede afectar la imagen al país sino a sus empresas, su población y sus productos. En este sentido, los estadounidenses destacan como aspecto positivo del país la pasión y la alegría; y como negativo la guerrilla, el terrorismo y la congestión vehicular. 
Los estadounidenses mayores de 40 años asocian a Colombia con las drogas, crimen y la inseguridad. A más edad del encuestado se mantiene una asociación histórica negativa, por lo cual se acepta la hipótesis. Los visitantes más jóvenes indican que la amabilidad, la pasión y la alegría de la gente son descriptores positivos de la imagen país de Colombia. Sin embargo, los visitantes independientemente de la edad, señalaron que la violencia, la inseguridad, las drogas y la guerrilla son descriptores negativos de la imagen país.

La percepción entre los visitantes y no visitantes está polarizada. Los jóvenes visitantes y no visitantes están interesados en conocer a Colombia, sin embargo se mantiene una percepción negativa sobre la imagen país asociada al tema de la inseguridad. Aún no se ha llegado a un consenso sobre cuáles son los elementos, las características o los rasgos que deben destacarse para fortalecer la imagen país que se proyecta en el extranjero, lo que genera una opinión difusa en cuanto al posicionamiento en el caso colombiano.

La amabilidad es un atributo que destacan los extranjeros como aspecto positivo de Colombia. También fue considera como la primera característica de los colombianos, seguida de alegría y diversión.

El café es el producto que mayor recordación presenta por parte de la población de estudio (ver Figura 10). El $65 \%$ de los extranjeros asocian a Colombia con el café. De acuerdo con lo anterior se confirma la hipótesis que Colombia mantiene un posicionamiento histórico por actividad productiva dado por su trayectoria cafetera.

Sin embargo, observando los resultados más detalladamente, se encuentra que estas asociaciones van cambiando según la edad, el país de procedencia y la categoría (visitante y prospecto).

Una imagen país percibida como positiva es importante para Colombia. Si la imagen es positiva, los visitantes exponen todo lo que viven de manera positiva, pero si la imagen percibida es negativa, esto no solo le puede afectar la imagen al país sino a sus empresas, su población y sus productos.

La imagen de Colombia debe reflejar el prestigio de su población, de sus empresas y de sus atributos naturales. La percepción juega un papel fundamental en la decisión de visitar o no a Colombia. El desafío para la estrategia de marca país es cautivar a los estadounidenses para aumentar su radio de visita o ubicar a Colombia como destino número uno en sus planes de viajes.

La imagen país de Colombia se utiliza como una herramienta de las relaciones públicas internacionales. En la promoción de Colombia en su totalidad de la imagen es inevitable recurrir a donde es la realidad. De acuerdo a los hallazgos, la percepción sobre la imagen país de Colombia tiene repercusiones en el turismo, las exportaciones y la inversión extrajera. En esa perspectiva, una imagen internacional positiva se convierte en un elemento esencial para mejorar la reputación de Colombia en mercados internacionales.

Para construir una imagen de un país, hay que construir sobre algo que une a la gente del país; no puede ser solamente simbólico, no puede ser solamente la palabra, tiene que estar basado en los valores que representa una nación.

Un aporte logrado en el campo de la presente investigación, es argumentar la estrategia de marca país frente a grupos de interés como: sociedad civil, empresas, gobierno y prescriptores. Sumado a que permitirá definir estrategias de marketing territorial ajustadas a cuatro segmentos (clúster) que fueron resultado del estudio.

El paso a seguir es desarrollar una investigación comparativa, sobre la percepción que tienen otros países sobre la imagen país de Colombia. Países como Venezuela y Ecuador, que en ese orden emiten el mayor número de visitantes hacia Colombia, después de Estados Unidos, son fuente valiosa de conocimiento sobre la percepción de la imagen país de Colombia.

\section{NOTAS}

1 Corresponde a los extranjeros que no han visitado a Colombia.

2 Bus escalera típico de Colombia, Ecuador y Panamá. 


\section{BIBLIOGRAFÍA}

Anholt, S. (s.f.). The Anholt-GfK Roper Nation Brands Index [en línea]. [Fecha de consulta: 23 agosto 2008]. Recuperado de http://www.gfkamerica.com/practice_areas/roper_pam/nbi_index/index.en.html

Asude, E. (2008). The Role of Image in International Relations: A Field Survey about the Image of Turkish Republic of North Cyprus in Kyrgyzstan. International Conference on Central Asia and North Cyprus Relations: Perspectives in Political, Economic and Strategic Issues.

Balabanis, G. y Diamantopoulos, A. (2011). Gains and Losses from the Misperception of Brand Origin: The Role of Brand Strength and Country-of-Origin Image. Journal of International Marketing, 19, 2, pp. 95-116. doi:10.1509/ jimk.19.2.95.

Bang-Jensen, J. y Gutin, G. (2009). Digraphs: theory, algorithms and applications ( $2^{\mathrm{a}}$ ed.). Heidelberg: Springer.

Bhakar, S. S., Bhakar, S. y Bhakar, S. (2013). Relationship between country of origin, brand image and customer purchase intention. Far East Journal of Psychology \& Business, 11, 1, pp. 50-71.

Birnberg, J. (1964). Bayesian Statistics: A Review. Journal of Accounting Research, 2, 1, pp. 108-116.

Capriotti, P. (2008). Planificación estratégica de la imagen corporativa. Barcelona: Ariel.

de Moura Engracia Giraldi, J., Ikeda, A. y Campomar, M. (2011). Reasons for country image evaluation: A study on China image from a Brazilian perspective. Journal of Database Marketing \& Customer Strategy Management, 18, 2, pp. 97-107. doi:10.1057/dbm.2011.10.

Diamantopoulos, A., Schlegelmilch, B. y Palihawadana, D. (2011). The relationship between country-of-origin image and brand image as drivers of purchase intentions. A test of alternative perspectives. International Marketing Review, 28, 5, pp. 508-524. doi:10.1108/02651331111167624.

Diestel, R. (2005). Graph theoryg (3a ed.). Heidelberg: Springer.

Dikčius, V. y Stankevičienè, G. (2010). Perception of country brand origin and countey of product manufacturing among Lithuanians and emigrants from
Lithuania. Organizations \& Markets In Emerging Economies, 1, 2, pp. 108-122.

Dinnie, K., Melewar, T., Seidenfuss, K. y Musa, G. (2010). Nation branding and integrated marketing communications: an ASEAN perspective. International Marketing Review, 27, 4, pp. 388-403. doi:10.1108/02651331011058572.

Elliot, A. y Maier, M. A. (2012). Color-incontext theory. Advances in Experimental Social Psychology, 45, pp. 63-125.

Gertner, D. y Kotler, P. (2002). Country as brand, product, and beyond: A place marketing and brand management perspective. Journal of Brand Management, 9, pp. 249-261.

Greenacre, M. (2008). La práctica del análisis de correspondencias [en línea]. Recuperado de http://www.fbbva.es/ TLFU/dat/greenacre_cap18.pdf

Harrison-Walker, L. (2011). Strategic positioning of nations as brands. Journal of International Business Research, 10, 2, pp. 135-147.

Jensen, F. y Nielsen, T. (2007). Bayesian Networks and Decision Graphs. New York: Springer.

Jetter, L. G. y Chen, R. C. (2011). Destination Branding and Images: Perceptions and Practices from Tourism Industry Professionals. International Journal of Hospitality \& Tourism Administration, 12, 2, pp. 174187. doi:10.1080/15256480.2011.564498.

Kotler, P., Bowen, J., Makens, J. C. y Moreno, R. R. (2003). Marketing para turismo. McGraw-Hill.

López Puga, J., García García, J., de la Fuente Sánchez, L. y de la Fuente Solana, E. (2007). Las redes bayesianas como herramientas de modelado en psicología. Anales de Psicología, 23, 2, pp. 307-316.

Malhotra, N. K. (2010). Marketing research: An applied orientation. Pearson.

Martínez, S. y Álvarez, M. D. (2010). Country Versus Destination Image in a Developing Country. Journal of Travel \& Tourism Marketing, 27, 7, pp. 748-764. doi:1 $0.1080 / 10548408.2010 .51968$.

Merriam, S. (2009). Qualitative Research: A Guide to Design and Implementation. San Francisco: Wiley.

Migración Colombia. (2014). Boletín Migratorio. Enero 2014. Bogotá.
Organización Mundial del Turismo (2007). Entender el turismo [en línea]. Recuperado de http://media.unwto.org/es/ content/entender-el-turismo-glosariobasico

Papadopoulos, N. y Heslop, L. (1993). Product-Country Images: Impact and Role in International Marketing. New York: International Business Press.

Pearl, J. (1988). Probabilistic reasoning in intelligent systems: networks of plausible inference. Los Altos: Morgan Kaufmann.

Plânlama Teşkilât, D. (2000). Tanıtma Özel ihtisas Komisyonu Raporu. Ankara: Devlet Plânlama Teşkilât.

Proexport Colombia. (2013). Informe Turismo Extranjero en Colombia [en línea]. Recuperado de http://www. proexport.com.co/sites/default/files/ informe_proexport_turismo_extranjero_en_colombia_a_junio_2013_version_final.pdf

Rangel, C. A. (1995). La sociedad colombiana y los problemas del narcotráfico. Colombia Internacional, 30, 39-46.

Salvador, M. (2001). Análisis de conglomerados o cluster [en línea]. Recuperado de http://www.5campus.org/leccion/ cluster

Salvador, M. (2003). Análisis de Correspondencias [en línea]. Recuperado de http://www.5campus.com/leccion/correspondencias

Stock, F. (2009). Identity, image and brand: A conceptual framework. Place Branding \& Public Diplomacy, 5, 2, pp. 118125. doi:10.1057/pb.2009.2.

Tunca, E. (2008). The Role of Image in International Relations: A Field Survey about the Image of Turkish Republic of North Cyprus in Kyrgyzstan. International Conference on Central Asia and North Cyprus Relations: Perspectives in Political, Economic and Strategic Issues, p. 2.

Turney, M. (2000). Images can be natural or constructed perceptions [en línea]. Recuperado de http://www.nku. edu/ turney/prclass/readings/image. html

Turnovsky, S. J. (1969). A Bayesian Approach to the Theory of Expectation. Journal of Economic Theory, 1, 2, pp. 220-227. 
Valls, J.-F. (1992). La imagen de marca de los países. Madrid: McGraw Hill.

Wang, C., Li, D., Barnes, B. R. y Ahn, J. (2012). Country image, product image and consumer purchase intention: Evidence from an emerging economy. International Business Review, 21, 6 pp. 1041-1051. doi:10.1016/j.ibusrev.2011.11.010.
Whetten, D. y Mackey, A. (2001). A social actor conception of organisational identity and its implications for the study of organisational reputation. Business \& Society, 41, pp. 393-414.

Zelanski, P. y Fisher, M. P. (2001). Color. Barcelona: Blume.
Zenker, S. y Martín, N. (2011). Measuring success in place marketing and branding. Place Branding \& Public Diplomacy, 7, 1, pp. 32-41. doi:10.1057/ pb.2011.5. 